\title{
The Role of Ultrasound in the Evaluation of Endometrial Receptivity Following Assisted Reproductive Treatments
}

\author{
Mitko Ivanovski \\ St. Lazar Hospital, Skopje \\ Macedonia
}

\section{Introduction}

Improvements in in vitro fertilization (IVF) and embryo transfer (ET) have resulted from evaluating each step of the process, analyzing effects of different techniques, then assessing outcomes to select the best method, whether related to preparation of the patient, choice of stimulation protocol, culture technique, embryo selection, mechanics of transfer, or posttransfer management. Despite numerous developments in assisted reproduction, the clinical pregnancy rate (CPR) in IVF and intracytoplasmatic sperm injection (ICSI) remains low. It has been estimated that up to $85 \%$ of the embryos replaced into the uterine cavity fail to implant (Edwards RG, 1995). The cause of this low CPR may reside in the technique of embryo transfer, the endometrial receptivity, or the capacity of the embryo to properly invade the endometrium.

Endometrial receptivity is defined as a temporary unique sequence of factors that make the endometrium receptive to the embryonic implantation. It is the window of time when the uterine environment is conductive to blastocyst acceptance and subsequent implantation. The process of implantation may be separated into a series of developmental phases starting with the blastocyst hatching and attachment to the endometrium and culminating in the formation of the placenta. The steps start with apposition, and progress through adhesion, penetration and invasion. Evaluation of endometrial receptivity remains a challenge in clinical practice.

Ultrasonography has an increasingly important role in the evaluation and treatment of infertility patients, being an efficient and cost-effective modality for studying the female reproductive organs and for monitoring functional changes during spontaneous and induced cycles (Blumenfeld et al., 1990; Goldberg et al., 1991).

Two-dimensional (2D) ultrasound imagining is limited by the movement of the transvaginal transducer in the narrow space of vagina. Therefore, it allows presentation of two planes: sagital and transverse. Real time ultrasonography allows us the study of two main implantation markers: endometrial thickness and endometrial morphological patterns. (Merce, 2002). Pulsed and color Doppler assessment is applied to the study of different variables of uterine and endometrial/subendometrial perfusion that are also used as receptivity factors (Fanchin, 2001). 
Three - dimensional (3D) sonography permits multiplanar display of all three sections: coronal, sagittal and transverse. The three-dimensional (3D) approach to assessing uterine receptivity, which considers endometrial thickness as well as volume, uterine artery Doppler and also endometrial tissue vascularization itself, might lead to a better understanding of this very specific and crucial endometrial preparation for implantation. The 3D technique allows reliable quantification of the two crucial phenomena-tissue remodeling pattern and tissue associated angiogenic dynamics - with quantification of the sub-endometrial vascular flow index.

The Embryo transfer (ET) procedure is the final important step in IVF process. It is a critically important procedure. No matter how good the IVF laboratory culture environment is, the physician can ruin everything with a carelessly performed embryo transfer. The entire IVF cycle depends on delicate placement of the embryos at the proper location of the endometrial cavity - with minimal trauma and manipulation. It has been suggested that ultrasound-guided ET (2D end 3/4D) facilitates ET and improves pregnancy rates, because it is thought that visualization of the cavity and the embryo deposition point have an advantage in comparison with blind ET technique.

\section{Assessment of the endometrium implantation markers with ultrasound}

Assessment of the endometrium has become a standard procedure during the diagnostic workup and treatment of infertility. Ultrasound sees the endometrium as a single thin line immediately after menstruation. This then expands under the influence of oestrogen in the follicular phase of the cycle to the typical trilaminar hypoechoic appearance. After ovulation there is little increase in size. The change to a secretory state is characterized by increasing echogenicity beginning at the periphery of the endometrium and progressing towards the midline over a period of $24-48 \mathrm{~h}$. The mature luteal endometrium appears homogenous and hyperechoic compared with the myometrium.

Real time ultrasonography allows us the study of three main possible implantation markers: endometrial thickness, endometrial volume and endometrial morphological patterns.

\subsection{Endometrial thickness}

Endometrial thickness is defined as the maximal distance between the echogenic interfaces of the myometrium and the endometrium, measured in the plane through the central longitudinal axis of the uterus.

Dynamic change in endometrial thickness in assisted conception cycles was first described by Rabinowitz et al. (1986). Using transvaginal scanning, Gonen et al.(1989) suggested that endometrial thickness, on the day before oocyte recovery, was significantly greater in pregnant than in non-pregnant women, and postulated that it may predict the likelihood of implantation. In IVF stimulated cycles, the endometrium increases $1.9 \mathrm{~mm}$ between days 7 and 9 of the stimulation treatment, $0.9 \mathrm{~mm}$ between days 9 and 11 and $0.6 \mathrm{~mm}$ between the latter and the day of hCG administration (Bassil et al.,2001). Significant differences have not been observed in endometrial thickness between hCG day and the day of embryo transfer (Khalifa et al., 1992), which clearly has practical implications to choose the timing for the measurement. In the conception cycles there is an accelerated increase in the endometrial 
thickness during the luteal phase that reaches significant differences regarding to that in non-conception cycles 14 days after the day of oocyte retrieval (Leibovitz et al., 1999; Rhabinowitz et al.,1986).

As an implantation marker, endometrial thickness is characterized by its significant sensitivity (95-100\%), but also shows a high number of false positives (78-97\%) (Friedler et al., 1996), therefore, the main advantage is a high negative predictive value $(87-100 \%)$. The main advantage of measuring endometrial thickness lies in its high negative predictive value in cases where there is minimal endometrial thickness. In IVF cycles, Khalifa et al. (1992) reported a minimal endometrial thickness of $7 \mathrm{~mm}$ to be accepted as a reliable sign of sub-optimal implantation potential. Although it is possible to achieve pregnancies with a thin endometrium (Remohi et al., 1997; Sundstrom 1998), this is always a bad predictive factor that requires further study of the endometrium (Noyes et al.,2001). It has also been reported that implantation, pregnancy and miscarriage rates are negatively affected by the endometrium being thicker than 14mm (Dickey at al., 1992; Noyes et al.,2001; Remohi et al.,1997; Weisman et al.,1999), although data from recent studies do not support this finding (Krampl and Feichtinger ,1993; Dietterich et al.,2002; Zhang et al.,2005). There is a positive correlation between increased endometrial thickness and pregnancy rates and further explained that this effect is dependent on the age of the patient, duration of stimulation, and embryo quality (Rabinowitz et al., 1986; Zhang et al., 2005). Contrary to these data, other studies show that measurement of endometrial thickness had no predictive value for pregnancy in ART (Fleischer et al., 1986; Glissant et al., 1985; Ivanovski et al., 2007a; Li et al., 1992; Welker et al., 1989).

Amir et al. (2007) reported that the possibility of a thick endometrium in IVF administered women over the age of 40 is less than that of the younger patient group; however, he also reported that pregnancy rate increases in the presence of thick endometrium.

Freidler et al. (1996) reviewed 2665 assisted conception cycles from 25 reports. Eight reports found that the difference in the mean endometrial thickness of conception and nonconception cycles was statistically significant, while 17 reports found no significant difference. They concluded that results from various trials are conflicting and that insufficient data exist describing a linear correlation between endometrial thickness and the probability of conception. There is not enough data to demonstrate if a linear relationship exists between endometrial thickness and the probability of pregnancy after an ART (Friedler et al., 1996).

\subsection{Endometrial volume}

Transvaginal 2D ultrasonography is an ideal non-invasive method for assessment of endometrium, but lacks specificity (Friedler et al., 1996). The use of 3 D ultrasonography to examine the uterine cavity in detail and reconstruct the images of the uterus surpasses the diagnostic potential of Two Dimensional (2D) ultrasound (Jurkovic et al., 1995; Lev-Toaff et al., 2001). Using two dimensional transvaginal ultrasound to measure endometrial thickness does not include the total volume of the endometrium (Friedler et al., 1996). Several studies have confirmed a high degree of reproducibility and accuracy of endometrial volume estimation using 3D ultrasound (Lee et al., 1997; Yaman et al., 2000). 


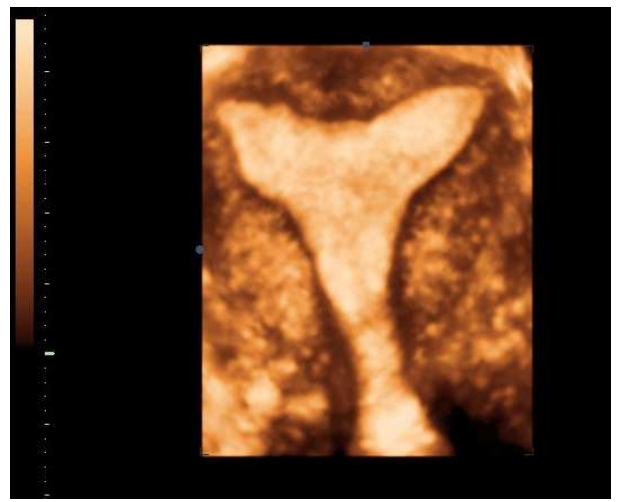

Photo 1. 3D Ultrasound of uterus and endometrium

3D US images can be obtained by two methods: freehand and automated. The freehand method requires manual movement of the transducer through the region of interest. The automated method acquires the images using dedicated 3D transducers. The digitally stored volume data can be manipulated and presented in various displays: multiplanar display, "niche" mode or surface rendering mode (Alcasar, 2006). Probably, the most used and useful display is multiplanar display, which simultaneously shows three perpendicular planes (axial, sagital and coronal), allowing navigation through these three planes with the possibility of switch over any desired plane. Another important ability of 3D US is volume calculation, even in irregularly shaped structures, using the Virtual Organ Computer-aided AnaLysis (VOCAL).

This method has been demonstrated to be more accurate than 2D-volume estimation, with an error estimation of 7\% for 3D US as compared of 22\% for 2D US (Yaman et al., 2003)]. Other investigators described a mean absolute error rate of $12.6 \%$ for two dimensional volume measurements, while the absolute error rate for 3D volume measurement was only 6.4\% (Riccabona et al., 1996).

During spontaneous menstrual cycles endometrial volume increased significantly during the follicular phase, reaching a plateau around the time of ovulation and remaining relatively stable throughout the luteal phase (Jakubkiene et al., 2006; Reine-Fenning et al., 2004). Parous women showed endometrial volumes significantly larger than nulliparous women (Reine-Fenning et al., 2004).

3D technology has added to daily practice in reproduction the use of endometrial volume as an implantation marker (Merce, 2004). Schild at al. (1999) was the first to correlate endometrial volume on the day of oocyte retrieval and pregnancy rate in an IVF program. They found that endometrial volume failed to predict outcome of IVF and that estradiol levels did not correlate with endometrial volume. Almost simultaneously, Raga et al. (1999) reported on 72 patients who underwent IVF cycle, using the same technique that Schild et al. (1999) for calculating endometrial volume but ultrasound examination was performed on the day of embryo transfer. These authors found that pregnancy rate was significantly lower $(15 \%)$ if endometrial volume was $<2 \mathrm{ml}$ than if it was $>2 \mathrm{ml}(34.5 \%)$. No pregnancy was achieved with endometrial volume below $1 \mathrm{ml}$. Yaman et al.(2000) reported subsequently in 
65 patients undergoing IVF program [47]. They found that endometrial volume did not differ significantly in women that became pregnant from those who did not. No pregnancy occurred of endometrial volume was $<2.5 \mathrm{ml}$. Zollner et al.(2003) evaluated endometrial volume in 125 women undergoing IVF. They found that pregnancy rate was lower in patients with endometrial volume $<2.5 \mathrm{ml}(9.4 \%)$ compared with those with endometrial volume $\geq 2.5 \mathrm{ml}(35 \%)$.

All studies more recently published have not demonstrated that endometrial volume is predictive for pregnancy after IVF program (Jarvela et al., 2005; Kupesic et al., 2001; Ng et al., 2006; Schild et al., 2000; Wu et al., 2003). This could be explained by methodological differences in volume calculation.

In our study clear morphology of the endometrium was obtained in 106 patients using 3D transvaginal ultrasound at the time of embryo transfer. The mean endometrial volume $( \pm 2 \mathrm{SD}$ ) vas $3.27 \pm 0.69$ (range $1.7-7.9$ ). Women were divided into three groups depending on the endometrial volume data: group 1: $<2 \mathrm{ml}$; group $2: 2-5 \mathrm{ml}$; group $3 ;>5 \mathrm{ml}$ respectively. No differences in age, number of days of ovarian stimulation, total, number of oocyte retrieved, and number of good quality embryios were found between these groups (table 1). Patients with an andometrial volume $<2 \mathrm{ml}$ (group1) had significantly $(\mathrm{p}<0.05)$ lower pregnancy and implantation rates as compared with the groups of women with $2-5 \mathrm{ml}$ (group 2) and $>5 \mathrm{ml}$ (group 3) endometrial volume. Moreover, no differences were observed between the latter two groups.

\begin{tabular}{lcccc}
\hline Parameter & $\begin{array}{c}\text { Group1: } \\
<\mathbf{2} \mathbf{~ m l}\end{array}$ & $\begin{array}{c}\text { Group 2: } \\
\mathbf{2 - 5} \mathbf{~ m l}\end{array}$ & $\begin{array}{c}\text { Group 3: } \\
\mathbf{5} \mathbf{~} \mathbf{~} \mathbf{l}\end{array}$ & $\mathbf{p}$ \\
\hline Cycles No & 30 & 42 & 36 & \\
\hline Age (years) & $35 \pm 0.9$ & $34 \pm 0.8$ & $32 \pm 0.5$ & NS \\
\hline Treatment (days) & $9.6 \pm 0.3$ & $9.3 \pm 0.49$ & $9.1 \pm 0.36$ & NS \\
\hline Oocytes retrieved No & $9 \pm 2.9$ & $11 \pm 2.1$ & $12 \pm 2.7$ & NS \\
\hline No embryo transfer & $2.4 \pm 0.5$ & $2.2 \pm 0.3$ & $25 \pm 0.6$ & NS \\
\hline No of pregnancies & $5(16.6 \%)$ & $14(33 \%)$ & $13(36 \%)$ & P<0.05 \\
\hline
\end{tabular}

Table 1. Patients grouped according to endometrial volume on the day of embryo transfer

An endometrial volume of $2.5 \mathrm{ml}$ on the day of embryo transfer has been proposed as a reliable threshold value to predict pregnancy after embryo transfer in IVF/ICSI cycles. However, again these findings lacked of specificity.

\subsection{Endometrial pattern}

Endometrial pattern is defined as the relative echogenicity of the endometrium and the adjacent myometrium as demonstrated on a longitudinal ultrasound scan. During the proliferative phase of the menstrual cycle the endometrium achieves a "triple line" morphology. In principle, the central echogenic line represents the uterine cavity; the outer lines represent the basal layer of the endometrium, or the interface between the endometrium and myometrium. The relatively hypo-echogenic regions between two outer lines and the central line may represent the functional layer of endometrium (Forest et al., 
1988). During the secretory phase of the menstrual cycle, the endometrium acquires a hyperechogenic morphology that is due to stromal edema, spirilization and secretion of the endometrial glands caused by the action of progesterone (Bassil et al., 2001; Fanchin et al., 2000; Fanchin et al., 2001; Leibovitz et al., 1999). However, since a correlation between echogenicity and progesterone has not been demonstrated (Bakos et al., 1993; Khalife et al., 1992) other factors such as androgen and gonadotropin effects could explain these changes (De Ziegler and Fancin, 1994; Tang and Gurpide, 1993).

Classification of the types of appearance of the endometrium has been simplified over time. Nowadays, intermediate patterns are often discarded and the endometrium is simply described as multilayered or non-multilayered (Sher et al., 1991; Smith et al., 1984). In a prospective study, Serafimi et al.(1994) found the multilayered pattern to be more predictive of implantation than any other parameter measured. The "triple line" endometrial pattern has high sensitivity (79-100\%) but an elevated percentage of false positives (57-91\%) also, subsequently it has an additional interest by its high negative predictive value $(75-100 \%)$. Although achieving a pregnancy with a "non triple-line" pattern is possible, its frequency is low (Tan et al., 2000).

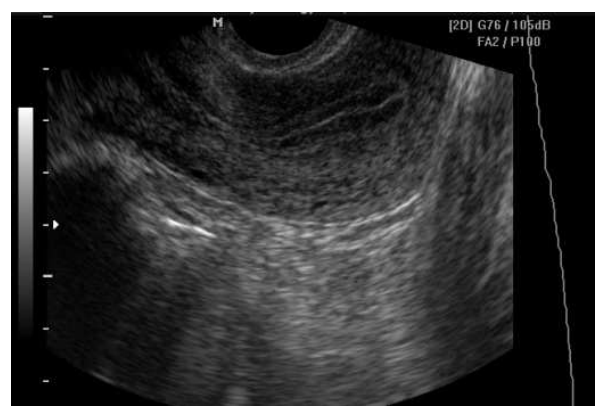

Photo 2. Multilayered endometrium

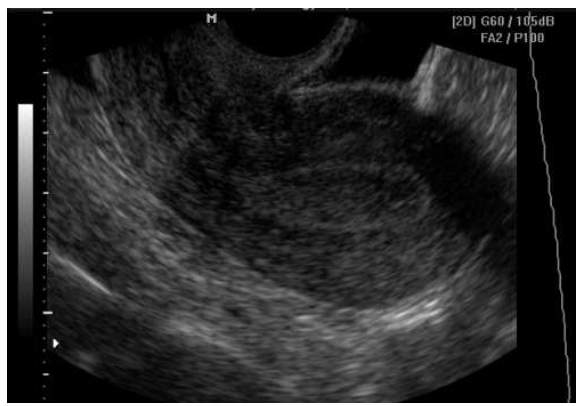

Photo 3. Non multilayered endometrium

The normal luteal endometrial pattern has been also implied as an implantation marker. A non-homogeneous hyperechogenic pattern 3 days after embryo transfer has been associated with lower pregnancy rates (Check et al., 2000). In addition, the midluteal endometrial pattern of women with unexplained infertility is related to the chance of pregnancy. The pregnancy rate is significantly higher when the endometrium displays a homogenous 
hyperechogenic pattern comparatively with non-homogenous pattern (Check et al., 2003). It is, however, important to emphasize that a poor endometrial pattern does not exclude pregnancy.

Our observation showed that $15(17.65 \%)$ patients have homogenous endometrium, and the other $70(82.35 \%)$ have triple line endometrium. There was not statistical significant difference, $\mathrm{p}>0.05(\mathrm{p}=1.00) /$ Fisher $)$ according pregnancy rates between both groups of patients (Table 2).

\begin{tabular}{lccc}
\hline Endometrial pattern & BHCG + & BHCG & Total \\
\hline Homogenous & 5 & 10 & 15 \\
\hline Total \% & 5.88 & 11.76 & 17.65 \\
\hline Triple line & 24 & 46 & 70 \\
\hline Total \% & 28.24 & 54.12 & 82.35 \\
\hline Total & 29 & 56 & 85 \\
\hline Total \% & 34.12 & 65.88 & 100 \\
\hline
\end{tabular}

Table 2. Endometrial pattern and pregnancy outcome

The effect of endometrial thickness and hyperechogenic pattern on determining pregnancy outcomes have been presented with various results. Increased endometrial thickness, endometrial pattern, and volume affect IVF outcomes, and this effect is dependent on patient's age, duration of stimulation, and embryo quality (Richter et al., 2007; Zhang et al., 2005). Tsai et al.(2000) reported that in ovulation induction by administering CC and gonadotropin and in IUI cycles, in terms of endometrial parameters, endometrial pattern has a significant effect on pregnancy positive and pregnancy negative patients; however, thickness and vascularity do not change pregnancy results. Fanchin et al. (2000) supported this view and reported that hyperechogenic endometrium deteriorates IVF outcomes.

Kepic et al.(1992) determined that endometrial thickness and pattern, follicle size and estradiol levels correlated to both the likelihood of pregnancy and subsequent outcome. Contrary to these data, other studies found no correlation between endometrial thickness, endometrial pattern and embryo implantation (Fleischer et al., 1986; Friedler et al., 1996; Ivanovski et al., 2007a; Rashidi et al.,2005). Such conflicting results can be explained by the variability of the endometrial appearance according to the timing of the ultrasound scan (day of human chorionic gonadotropin administration, day of oocyte pick-up or day of embryo transfer). It seems that the most promising data are obtained when the study is performed on the day of human chorionic gonadotropin (hCG) administration, since progesterone production does not interfere with endometrial characteristics at this period of the menstrual cycle.

\subsection{Uterine artery blood flow}

The introduction of transvaginal Doppler ultrasound makes the measurement of uterine artery blood flow possible, with hope that uterine arterial resistance changes might reflect receptivity of endometrium (Fleischer et al., 1991; Goswamy et al., 1988; Steer et al., 1994;). Color Doppler signals are measured at the uterine arteries and their ascending branches located in the outer third of the myometrium. 
Steer et al.(1994) used transvaginal color Doppler to study the uterine arteries in 23 normally cycling women, and they found that the lowest pulsatility index (PI) occurred 9 days after the LH peak. This indicates that the maximum uterine perfusion occurs at about the time of expected implantation. Another index of blood flow, the resistance index, was measured on the day of embryo transfer in a series of women undergoing IVF, and it was found to be lower in those who subsequently became pregnant.

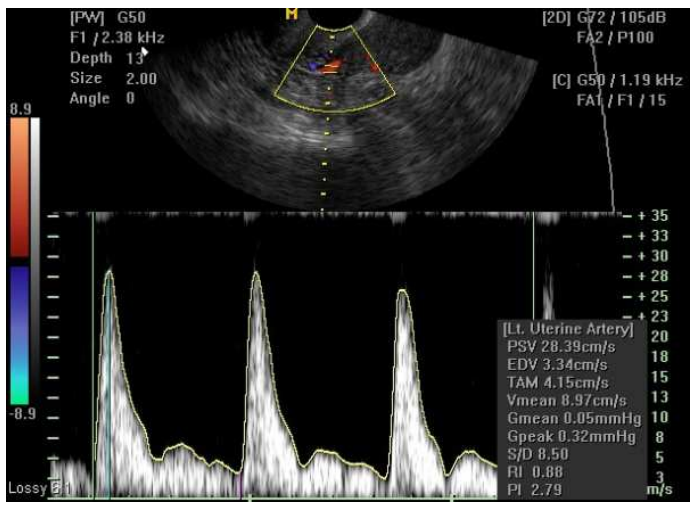

Photo 4. Arteria uterine blood flow

Doppler Studies have demonstrated the uterine and endometrial arteries resistance decreases significantly during the mesoluteal phase, i.e. in the period of embryo implantation (Agrawal et al., 1999; Bourne et al., 1996; Scholtes et al., 1989; Sladkevicius et al., 1993; Tan et al., 1996). It is probable that these vascular changes play a significant role in the implantation process because they are present from the beginning of the embryo nidation.

Sterzik et.al (1989) reported that the resistance index measured on the day of embryo transfer in IVF cycles was significantly lower in patients who subsequently became pregnant as compared with those who failed to achieve pregnancy.

Steer et al. (1992) have used transvaginal color Doppler to study the uterine arterial blood flow in 82 women undergoing IVF on the day of embryo transfer. The PI was calculated and the patients were grouped according to whether the PI was low (1-1.99), medium (2-2.99) or high (3.0+). There were no pregnancies in the high PI group and the PI was significantly lower in the women who become pregnant as compared with those who did not. However, although measurement of uterine artery blood flow impedance on the day of embryo transfer may be able to predict pregnancy, it would be more useful to detect flow abnormalities earlier in the cycle. To investigate this Zaidi et al.(1996) recently measured uterine artery PI in 135 women undergoing IVF on the day of hCG injection. They found significantly lower implantation rates in women with uterine artery PI $>3.0$. The authors suggested that the PI on the day of embryo transfer could be used to alter the management, such that a high value $(>3)$ would lead to elective freezing of the embryos for transfer at a later date in a more favorable cycle. If the PI is normal, the number of embryos transferred could be reduced to minimize the risk of a multiple pregnancy. 
The ability of Color Doppler - PI to predict uterine receptivity presents high sensitivity (96$100 \%)$ and a high negative predictive value (88-100\%) although it has low specificity (13$35 \%$ ) and positive predictive value (44-56\%) (Friedler et al., 1996). Inadequate blood flow would thus prevent implantation, although optimal uterine profusion does not always imply pregnancy. In addition to this, high uterine resistance is observed in less than $10 \%$ of non-conception cycles, suggesting that this parameter is responsible for implantation failure in very few cases (Caccitore et al., 1996).

In our study, uterine artery and arcuate artery blood flow were measured with color Doppler ultrasonography at the hCG day. The average values of right or left uterine and intraovarian artery PI, RI, and Vs values were used in the analysis. In the pregnant group average uterine artery PI and RI were significantly lower than in the non-pregnant group. Arcuate artery RI in the pregnant group was significantly lower than that in the nonpregnant group. (Table 3).

In our results, there were statistically significant lower mean uterine artery PI and RI, arcuate artery in the pregnant group than in the non-pregnant group $(P<0.05)$. Arcuate artery PI value was lower in the pregnant group than in the non-pregnant group, but this did not reach statistical significance. Peak systolic velocity (Vs) values in both the mean uterine artery and arcuate artery were higher in the pregnant group than in the nonpregnant group; however, the difference was not statistically significant.

Vascular impedance was calculated with PI, RI, and Vs values, among which PI was found to be the most important. Optimal uterine receptivity can be accomplished by reduced vascular resistance and increased blood flow, which will improve pregnancy success. We suggest the use of transvaginal color Doppler ultrasonography to measure the blood flow in uterine arteries, arcuate arteries before hCG in IVF cycles.

\begin{tabular}{|c|c|c|c|c|c|}
\hline \multirow[b]{2}{*}{ Prameter } & \multicolumn{2}{|c|}{ Doppler values } & \multirow[b]{2}{*}{$t$} & \multirow[b]{2}{*}{ Z } & \multirow[b]{2}{*}{$\mathrm{p}$} \\
\hline & (29) BHCG + & (56) BHCG - & & & \\
\hline RI Aut HCG & $0.71 \pm 0.06$ & $0.89 \pm 0.07$ & -6.65 & & $0.000^{* * *}$ \\
\hline PI Aut HCG & $1.83 \pm 0.14$ & $2.19 \pm 0.27$ & & -4.79 & $0.000^{* * *}$ \\
\hline PVs Aut HCG & $21.11 \pm 3.47$ & $0.83 \pm 0.07$ & 3.04 & & $0.003^{* *}$ \\
\hline RI a.arcuata HCG & $0.56 \pm 0.05$ & $0.71 \pm 0.06$ & -3.69 & & $0.000^{* * *}$ \\
\hline PI a.arcuata HCG & $1.07 \pm 0.09$ & $1.29 \pm 0.09$ & -4.09 & & $0.000^{* * *}$ \\
\hline P Vs a.arcuata & $11.07 \pm 2.71$ & $7.19 \pm 2.94$ & -3.17 & & $0.004^{* *}$ \\
\hline
\end{tabular}

Table 3. Average Doppler values in pregnant and non-pregnant group on HCG day

Although pregnancy outcome tended to be poor in patients with higher mean uterine arterial impedance indices, the predictive value of using a specific resistance index (RI) or pulsatility index (PI) variable in assessing endometrial receptivity seems to be limited (Tekay et al., 1996; Friedler et al., 1996). One of the explanations is that the major uterine compartment is the myometrium and not the endometrium, and thus most of the blood passing through the uterine arteries never reaches the endometrium. These contradictory results are due to significant methodological variations such as the ovarian stimulation protocol used, the cycle's day when the Doppler study was carried out or the sonographic examination route (Merce et 
al., 2000). A more logical approach would be to evaluate the vascularization around the endometrium directly in an attempt to assess endometrial receptivity.

\subsection{Endometrial / subendometrial blood flow}

The assessment of the endometrial receptivity is the key for success of all ART procedures. Angiogenesis plays a critical role in various female reproductive processes such as development of a dominant follicle, formation of corpus luteum, endometrial growth and implantation (Demir et al., 2006; Nardo, 2005; Sherer and Abulafia, 2001). For this reason many researches have paid attention to ovarian and uterine/ endometrial vascularization for predicting outcome in IVF programs (Tekay et al., 1995). Invent of the Doppler in ultrasound has significantly improved the understanding of morphological changes occurring in the ovary and the uterus as a reflection of biochemical changes during the menstrual cycle. The vascular changes are reflection of the biochemical changes and can be studied by color Doppler. The spectral/pulse Doppler values give objective assessment of the endometrial vascularity. Therefore, color and pulse Dopplers speak about functional maturity of the endometrium. 3D ultrasound and 3D power Doppler assesses the global vascularity, as compared to vascularity in a single plane on 2D ultrasound and so may give better idea about follicular maturity and endometrial receptivity and therefore implantation rates.

A good blood supply towards the endometrium is usually considered to be an essential requirement for implantation and therefore assessment of endometrial blood flow in IVF treatment has attracted a lot of attention in recent years.

Doppler study allows us to evaluate endometrial blood flow by means of analyzing flow velocity waveforms of subendometrial and endometrial arteries (Achiron et al., 1995; Battaglia et al., 1997; Ivanovski et al., 2007b; Merce et al., 1995; Schild et al., 2001; Yuval et al., 1999; Zaidi et al., 1995) and the color mapping by two-dimensional (Applebaum, 1995; Battaglia et al., 1997; Chien et al., 2002; Yang et al., 1999; Zaidi et al., 1995) or three-dimensional ultrasound (Jarvela et al., 2005; Kupesic et al., 2001; Ng et al., 2006; Wu et al., 2003).

Blood vessels of the uterus and endometrium can be detected by color and power Doppler ultrasound where endometrium and myometrium constitute an anatomical and functional unit. Uterine arteries branch off the internal iliac arteries. Ultrasonically, they look like hyperechoic structures running along the cervix and the isthmic part of the uterus. Arcuate arteries are tortuotic anechoic structures that spread through myometrium. Radial arteries penetrate vertically the myometrial layers of smooth muscle cells and divides after passing through the myometrial-endometrial junction to form the basal arteries that supply the basal portion of the endometrium, and the spiral arterioles that continue up toward the endometrial surface and supply stratum functionale of endometrium. Their shape and size change during menstrual cycle and they shed during menstruation together with the glandular tissue. During pregnancy, these arteries become uteroplacental decidual arteries. Basal arterioles supply endometrial stratum basale. The vessels in genital tract undergo cyclic changes dictated by the hormonal cycle.

At the myometrial- endometrial junction, a specific subendometrial area can be identified as a thin hypoechoic layer between the echogenic endometrium and myometrium on ultrasound examination (McCarthy et al., 1989; Scoutt et al., 1991; Tetlow et al., 1999). Different authors ascribe different names to this layer: junctional zone, inner myometrium, 
subendometrial halo and subendometrial layer are all synonymous. The layer can be viewed by either ultrasound or MR ( Killick, 2007). Histological studies have confirmed that the subendometrial halo surrounding the endometrium represents the innermost layer of the myometrium, and compared with the outer myometrium, it consists of a distinct compartment of more tightly packed muscle cells with increased vascularity (Lesny et al., 1999; Turnbull et al., 1995), suggesting a modified function. Many studies have shown that interactions between the junctional zone and the endometrium may play an important role in the implantation process (Chien et al., 2002; Salle et al., 1998).

Conventionally, pulsed and color Doppler have been used to assess uterine and endometrial blood flow. However, conflicting results have been reported.

Subendometrial radial arteries pulsatility was the only parameter that improved in those cycles where pregnancy was achieved after a previous non-conceptional cycle, except when implantation failed and subsequently a miscarriage or ectopic pregnancy was diagnosed (Merce et al., 1995; Merce et al., 2000a, 2000b).

While some authors (Kupesic et al., 2001) have found that vascular resistance in the endometrial spiral arteries or the subendometrial radial arteries, also called intramyometrial subendometrial arteries (Merce et al., 1995; Merce et al., 2000) was significantly lower on the day of oocyte retrieval or embryo transfer in patients who achieve pregnancy (Battaglia et al., 1997; Ivanovski et al., 2004; Kupesic et al., 2001) others have found no differences (Schild et al., 2001; Yuval et al., 1999; Zaidi et al., 1995).

Now, with the advance of ultrasonography, color Doppler energy imaging has been used in endometrial blood flow assessment. Color Doppler energy is a technology based on the total integral of energy frequency spectrum. It visualizes blood flow with the energy of moving reflectors and enjoys the advantages of high sensitivity to slow blood flow, while being less dependent on angles and providing a less cluttered image. In general, endometrial color mapping has been evaluated in a subjective way although the color area can also be quantified (Yang et al., 1999).

Color mapping of endometrial vascularity can be classified in various types according to the degree of penetration into the endometrial thickness, using conventional color (Applebaum, 1995; Battaglia et al., 1997; Zaidi et al., 1995) or power Doppler (Merce et al., 2002).

The zones of vascularity are defined according to Applebaum (1995) as: zone 1 when the vascularity on power Doppler is seen only in the myometrium surrounding the endometrium; zone 2 when vessels penetrate through the hyperechogenic endometrial edge; zone 3 when it reaches internal hypoechogenic zone and zone 4 when they reach the endometrial cavity.

The absence of color mapping of the endometrium and subendometrial areas means an absolute implantation failure (Zaidi et al., 1995) or a significant decrease (80) of the implantation rate. Conversly, the pregnancy rate increases when the vessels reach the subendometrial halo and endometrium (Zaidi et al., 1995; Chien et al., 2002). The presence of vessels within the endometrium is associated with a thicker endometrium, which suggests a correlation between the endometrial perfusion and endometrial growth. On the other hand, the absence of endometrial-subendometrial blood flow is accompanied by a high uterine artery resistance (Chien et al., 2002). 


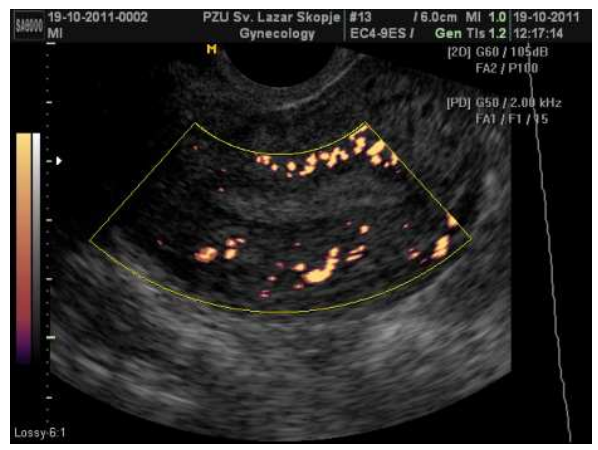

Photo 5. Zone 1 of vascularity

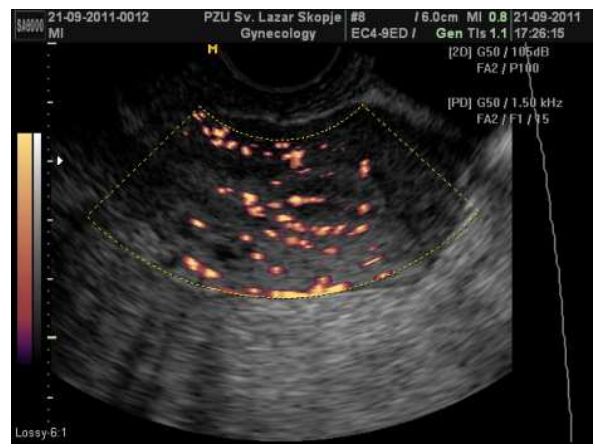

Photo 6. Zone 4 of vascularity

We investigated the correlation of blood flow in the endometrial- subendometrial region detected by Power Doppler sonography with pregnancy outcome of an IVF-ET program. The endometrial-subendometrial blood flow distribution pattern was determined by demonstrating pulsatile color signals in the subendometrial and endometrial regions. For those with vascularization penetrating the subendometrial area, we adopted the definition from Applebaum (1999), summarized as follows: group1, vessels penetrating the outer hypoechogenic area surrounding the endometrium but not entering the hyperechogenic outer margin; group 2, vessels penetrating the hyperechogenic outer margin of the endometrium but not entering the hypoechogenic inner area; and group 3: vessels entering the hypoechogenic inner area in endometrial cavity.

The degree of vascular penetration into the endometrium in relation to pregnancy outcome is shown in Table 4. Although pregnancy rates were significantly higher in patients with group 3 penetration compared with group 1 ( $\mathrm{P}<0.001)$ or group 2 penetration, there was no significant difference between the groups with zone 1 and zone 2 penetration. There were also significant differences in miscarriage rate: on group of patients without flow was significantly higher than that of those in group 2 or group $3(50 \%$ vs. $12.5 \%$ or $7.14 \%$; $\mathrm{P}<0.001$, respectively).

There was significant correlation between group with higher miscarriage rate (S-; E-) and higher uterine artery PI (> 2,9) and RI (>0.96) values. 


\begin{tabular}{cccccc}
\hline & Subend. Flow & Subend. Flow & \multicolumn{3}{c}{ Vascular penetration } \\
\hline & Present & Absent & Group 1 & Group 2 & Group 3 \\
\hline BHCG + & 85 & 21 & 23 & 38 & 24 \\
\hline BHCG - & $36(42.35 \%)$ & $4(19 \%)$ & $6(26 \%)$ & $16(42 \%)$ & $14(53 \%)$ \\
\hline Miscariage rate & 49 & 17 & 17 & 22 & 10 \\
\hline
\end{tabular}

Table 4. Pregnancy and implantation rates in relation to the presence or absence of subendometrial blood flow and zone of vascular penetration.

The report from Li-Wei Chien et al.(2002) showed that the absence of subendometrial blood flow is associated with poor pregnancy outcome; however, this condition is not indicative of a non-receptive endometrium as suggested in our and other study (Zaidi et al., 1995). Although women with no detectable endometrial/subendometrial flow on the day of ET tend to be older, it is noteworthy that more than half (9 of 14,54.5\%) of pregnancies in such women aborted spontaneously. Although these data suggest that development of the endometrial vessel system may play a role in maintaining pregnancy in the early stages, but the case number is too small to draw any conclusion.

The three-dimensional ultrasound allows studying not only the endometrial volume but also the quantitative assessment of vessels density and blood flow within the endometrium and subendometrial region. Vascularization of tissues within the region of interest can be assessed using 3D Power-Doppler angiography and the VOCAL program (Pairleinter et al., 1999). Using this method, three vascular indexes can be calculated: the Vascularization Index (VI), expressed as percentage, measures the number of color voxels in the studied volume, representing the blood vessels within the tissue. The Flow Index (FI) is the color value of all color voxels, representing average color intensity. And the Vascular-Flow Index (VFI) is the average color value of all grey and color voxels, which represents both blood flow and vascularization. Using the "shell" function it is possible to calculate a volume at different thickness around the predetermined endometrium and estimate the vascularization in this "shell". This allows the assessment of the so called "subendometrial region" 3D US has a very low inter-observer and intra observer variability for calculating endometrial volume, with intraclass correlation coefficients $\geq 0.97$ (Bordes et al., 2002; KeyMensah et al., 1996; Raine-Fenning et al., 2002b; Yaman et al., 1999). However, this depends on the technique used, being the VOCAL method the most reproducible (Reine-Fenning et al., 2003). This technique has been also found to be highly reproducible for estimating ovarian and endometrial vascularization using 3D PD with intraclass correlation coefficients $\geq 0.99$ for all indexes (Alcazar et al., 2005; Raine-Fenning et al., 2002a; Jarvela et al., 2003).

Endometrial and subendometrial blood flows assessed in the same patients by 3D power Doppler indices are significantly lower in stimulated than in natural cycles. ( $\mathrm{Ng}$ et al., $2004 \mathrm{~b})$ It has also been reported that endometrial and subendometrial blood flow are negatively affected by serum estradiol concentrations, but they are not affected by other factors such as women age, smoking habits, or types of infertility or parity during IVF treatment. (Ng et al., 2006)) This fact could explain that ovarian hyperresponders tend to have lower endometrial and subendometrial blood flows during the early luteal phase $(+2$ hCG day). (Ng et al., 2004a) 
A reduced endometrial blood flow after ovulation could be related to an increased uterine contractility (Hauksson et al., 1998) and may lead to endometrial hypoxia during the implantation period (Fischer et al., 1993).

Some authors have provide that subendometrial vascularity indices may behave as predicting factors for pregnancy (Kupesic et al., 2001; Wu et al., 2003), on the other hand other authors prefer to calculate only the 3D power Doppler indices of the endometrium (Merce, Donald School Textbook, 2008 ). Even though most authors assess both endometrial and subendometrial vascularization as a pregnancy predictor (JARVELA ET AL., 2005; Kupesic et al., 2001; Ng et al., 2006; Wu et al., 2003).

Schild at all.(2000) evaluated 96 patients undergoing IVF program by 3D-PDA. Only subendometrial vascularization was assessed. They found that all 3D-PDA indices were significantly lower in conception with non-conception cycles. However, a great overlapping existed. These findings were the same in a subgroup of patients in which at least two good quality embryos were transferred. Logistic regression revealed that subendometrial FI was the strongest predicting factor of IVF success. No association between uterine artery PI and PSV and IVF outcome was found.

On the other hand, Raine-Fenning (2004) found that endometrial and subendometrial vascularity were significantly reduced in women with unexplained subfertility during the mid-late follicular phase, irrespective of estradiol or progesterone concentrations.

A scoring system reported by Kupesic et al. (2004) for uterine receptivity, done on the day of embryo transfer, shows that subendometrial $\mathrm{FI}<11$ was a cut off limit. No pregnancies occurred when it was $<11$ and the conception group showed its values of 13.2 \pm 2.2 . No significant differences were found in subendometrial VI and VPI between conception and non-conception cycles. These results were opposite to those reported by Schild et al. (2000).

$\mathrm{Wu}$ at al. (2003) reported that subendometrial VFI was significantly higher in those patients who become pregnant. The best prediction rate was achieved by a subendometrial VFI > 0.24 , with a sensitivity of $83.3 \%$, specificity of $88.9 \%$, positive predictive value of $93.8 \%$ and negative predictive value of $93.8 \%$ and negative predictive value of $72.7 \%$.

Järvelä at al.(2005) evaluated endometrial and subendometrial vascularization by 3D PDA using the VOCAL program with a $15^{\circ}$-rotation step. They did not find differences on endometrial and subendometrial vascularization between conception and non-conception cycles. However, they found than in both conception and non-conception cycles endometrial and subendometrial VI decreased significantly between the two examinations this finding would be in agreement with the findings of Raine-Fenning et al. (2004) in natural cycles, who reported a decrease of endometrial vascularity during the periovulatory period.

Whereas $\mathrm{Ng}$ et al (2004) documented a lower endometrial VI and VFI in pregnant group on the day of oocyte retrieval and also a non-significant trend of higher implantation and pregnancy rates in patients with absent subendometrial and endometrial flow. This probably can be explained on the basis that hCG administration/LH peak causes increased uterine artery resistance and hence a decrease in endometrial perfusion on the day of oocyte retrieval. This also correlates with the observation by $\mathrm{Ng}$ et al, (2006) which says that subendometrial vascularization flow indices are significantly lower in patients with uterine artery $R I \geq 0,95$. Multiple logistic regression analysis showed that from multiple parameters only the number 
of embryos replaced and endometrial VI significantly improved the chance of pregnancy, but this latter had only a marginal predictive value (odd ratio: 0.87, 95\% CI: 0.76-0.99).

These findings are in agreement with those reported by Schild et al.(2000) ; Ng et al (2006); who did not find differences in endometrial/ subendometrial VI, FI and VFI between pregnant and non-pregnant women when at least two good quality embryos was transferred. However, when first one or no good quality embryos were transferred all three endometrial VI, FI and VFI were significantly higher in those women who became pregnant as compared with those who did not. These data could indicate that endometrial vascularization might be a non-relevant factor when good quality embryos are transferred but could be an important factor when no quality embryos are transferred.

These conflicting results might be explained by the fact of different timing when performing 3D-PDA assessment.

Our study, performed on ET day, showed that when endometrial FI was $<20,17 \%$ of patients became pregnant; $\mathrm{FI}=20-40,35 \%$ became pregnant and when $\mathrm{FI}>40,45 \%$ of patients became pregnant. The higher FI values correlate with pregnancy outcome (Table 5).

Also, higher VFI significantly associated with higher pregnancy rates. When endometrial VFI was $>20.55 .5 \%$ patients became pregnant, and when VFI $<2$, no conception was seen (Table 6).

\begin{tabular}{cccc}
\hline End FI/Pregnancy rates & $\mathbf{2 0}$ & $\mathbf{2 0 - 4 0}$ & $>\mathbf{4 0}$ \\
\hline BHCG + & 6 & 21 & 5 \\
\hline BHCG - & 31 & 48 & 6 \\
\hline Total & $35(17.1 \%)$ & $60(35 \%)$ & $11(45 \%)$ \\
\hline
\end{tabular}

Table 5. Endometrial FI and pregnancy rate

\begin{tabular}{ccccc}
\hline End VFI/Pregnancy rates & $<\mathbf{2}$ & $\mathbf{2 - 1 0}$ & $\mathbf{1 1 - 2 0}$ & $>\mathbf{2 0}$ \\
\hline BHCG + & $/$ & 20 & 7 & 5 \\
\hline BHCG - & 10 & 46 & 14 & 4 \\
\hline Total & 10 & $66(30.3 \%)$ & $21(33.3 \%)$ & $9(55.5 \%)$ \\
\hline
\end{tabular}

Table 6. Endometrial VFI and pregnancy rate

Summary, regarding the role of endometrial and subendometrial vascularity assessment the results of several studies are clearly controversial (Kupesic et al., 2001; Jarvela et al., 2005; $\mathrm{Ng}$ et al., 2005; $\mathrm{Ng}$ et al., 2006; Wu et al., 2003. An explanation for these controversial findings might be the different design of reported studies, specially the timing of ultrasound evaluation. A consensus about the timing of this technique to be used within an IVF program is needed to establish more precise values for endometrial VI, FI and VFI, in order to design new further prospective studies.

On the other hand, the concept of evaluating uterine receptivity by a uterine score including the endometrial blood flow was first introduced by Applebaum (1995). With the absence of subendometrial blood flow, even in the presence of other favorable parameters, no 
conception was achieved. By using a similar approach, Salle et al. (1998) calculated a uterine score in the secretory phase of the menstrual cycle preceding IVF. Vascularization was considered to be positive if more than three vessels penetrating the outer hypo-echogenic area surrounding the endometrium could be seen. None of the individual ultrasonographic or Doppler parameters tested was of sufficient accuracy to predict uterine receptivity, whereas the uterine score seemed to be a useful predictor of implantation.

However, research by $\mathrm{Ng}$ et al. (2006) reported no relationship between endometrial thickness, morphology and pregnancy outcome. End in a recent study, endometrium pattern, endometrium thickness, and end-diastolic blood flow was shown to be the most effective combination for evaluation of uterine receptivity (Dechaund et al., 2008)). Kupesic et al. (2001) compared the 2-D and 3-D ultrasonographic scoring systems by combining parameters including endometrial thickness, volume, echogenicity, and subendometrial blood flow and found the two systems had similar efficiencies in predicting pregnancy outcome of IVF-ET procedures. $\mathrm{Ng}$ at al. (2009) discuss the relationship of endometrial blood flow between those who with a thin $(\leq 8 \mathrm{~mm})$ endometrium and those with a low volume $(\leq 2.5 \mathrm{ml})$ endometrium. It was found that 3D power Doppler flow indices of the endometrial and subendometrial regions were significantly lower in patients with a low volume endometrium compared with those with a normal volume endometrium. Endometrial end subendometrial vascularity measured by 3D power Doppler ultrasound was significantly lower $(\mathrm{p} \leq 0.003)$ in patients with a low volume endometrium, but not in those with a thin endometrium. Merce et al. (2008) conclude that endometrial volume and 3D power Doppler indexes are statistically significant in predicting the cycle outcome.

In summary, although 2D and 3D Doppler ultrasound seems to be very interesting tool for assessing the endometrial/subendometrial blood flow in assisted reproductive treatments, its current clinical value in predicting pregnancy in IVF should be considered as limited in view of the controversial results published to date. Though still larger studies are needed to established more precise ultrasound values/parameters to understand the endometrial physiological status better and achieve better pregnancy rates with ART procedures.

\section{Ultrasound and embryo transfer}

The vast majority of transferred embryos fail to implant in spite of improvements in ovulation induction, fertilization and embryo cleavage. On average, up to $90 \%$ of apparently healthy zygotes transferred in utero are destined to vanish, giving no signs of trophoblastic attachment and production of human chorionic gonadotrophin (HCG) (Nikas et al.,1999) The main variables that affect nidation are related to uterine/endometrial receptivity, embryo quality and the efficiency of embryo transfer.

The Embryo transfer (ET) procedure is the final important step in IVF process. It is a critically important procedure. No matter how good the IVF laboratory culture environment is, the physician can ruin everything with a carelessly performed embryo transfer. The entire IVF cycle depends on delicate placement of the embryos at the proper location of the endometrial cavity with minimal trauma and manipulation.

Apart from embryo quality and the age of the patient, success rates after embryo transfer seem to be mostly dependent on factors that relate to the degree of trauma that is inflicted 
upon the endometrium and myometrium during the transfer procedure. Rigid catheters, blood contamination of the tip, increased myometrial contraction waves and the level of difficulty in introducing the catheter inside the uterine cavity all tend to reduce the probability of implantation of the embryo (Buckett, 2003;Gonen et al., 1991; Goudas et al., 1998; Fanchin et al., 1998; Levi Setti et al., 2003; Lesny et al., 1998; Mansour et al., 1990; Mansour and Aboulghar, 2002; Meriano et al., 2000; Mirkin et al., 2003; Sallam and Sadek, 2003; Schoolcraft et al., 2001; Visser et al., 1993; Wisanto et al., 1989). Also, pregnancy rates may vary greatly among individual providers (Hearns-Stokes et al., 2000; Karande et al., 1999).

The technique used in the transfer procedure may be of importance by allowing for more or less traumatic procedures. The 'clinical touch' method was first described by Steptoe and Edwards and is a well-known technique for embryo transfer (Steptoe and Edwards, 1976). This technique consists of the insertion of a catheter into the cavity until touching the fundal endometrium, followed by a $5 / 10 \mathrm{~mm}$ retreat and subsequent deposition of the embryos. The difficulties and uncertainties of this method have been widely questioned. One of these uncertainties is related to the fact that transfers based only on the sensitivity of the operator are associated with discrepancies between the presumed and true position of the catheter, especially considering the different levels of clinical experience (Buckett, 2003; Hurley et al., 1991; Levi Setti et al., 2003; Sallam and Sadek, 2003; Woolcott and Stanger, 1997).

Waterstone et al. (1991) suggested that the site of deposition of the embryos within the uterine cavity could have profound effects on success rates. Later this finding was also substantiated by Naaktgeboren (1998). By applying a technique in which the embryos are expelled at a fixed distance from the external os, a remarkable decrease was observed in the variability in success rates among physicians: most physicians approximated the success rates of the best-performing physician (Naaktgeboren et al., 1997, 1998). The wide variability between clinicians working in the same center (which to an extent nullifies the potential difference in the laboratory circumstances) clearly demonstrates the role of the clinician in embryo transfer and the magnitude of problem. A possible explanation for this effect may be that replacing embryos in the middle part of the uterus without touching the fundal endometrium allows for a less traumatic embryo transfer, especially for those physicians who have difficulties with approaching the fundal endometrium gently.

Ultrasound-guided embryo transfer (UGET) during an IVF cycle was initially reported during the mid-1980s (Leong et al., 1986; Strickler et al., 1985) and has gradually become an integral part of the embryo transfer technique for many IVF clinics. The potential advantages of this technique compared with standard embryo transfer (performed by clinical feel) include the ability to visualize the uterocervical angle which may aid with difficult transfers, reliably determine the catheter distance from the fundus at the time of embryo transfer, and visualize any unforeseen uterine abnormalities before the transfer. Some studies have demonstrated a benefit in favor of UGET when compared to embryo transfer without ultrasound guidance (Coroleu et al., 2000; Ivanovski et al., 2006; Matorras et al., 2002; Prapas et al., 2001; Sallam et al., 2002; Tang et al., 2001) although others have not (Al-Shawaf et al., 1993; Garcia-Velasco et al., 2002; Kan et al., 1999). Careful examination of the data from four properly randomized clinical trials (Coroleu et al., 2000; Garcia-Velasco et al., 2002; Matorras et al., 2002; Tang et al., 2001) showed a significant advantage to UGET with regard to implantation, clinical pregnancy, and ongoing pregnancy rates (Buckett, 2003; Sallam and Sadek, 2003). 
It has been described that Mock Embryo Transfer (MET) in a cycle preceding the actual IVF procedure or immediately before the actual transfer procedure might provide information about what to expect during the ET and thereby facilitate the procedure (Sharif et al., 1995). In one randomized controlled trial employing the "dummy transfer" it was stated that this procedure could influence the choice of catheter and could improve pregnancy rates (Mansour et al., 1990).

Shamonki at al. (2005a) proposed that ultrasound guided trial transfer (UTT) in the office can be performed as an alternative to UGET for most patients. UTT can theoretically identify those patients with a discrepancy between perceived and actual uterine cavity length in an office setting where logistical issues are of less concern, and thus save UGET for only a select minority of patients where the trial transfer was challenging. The data from their study demonstrate that UTT can be useful method in identifying patients who will otherwise have an inaccurate trial transfer if the procedure were done blindly (Matorras et al., 2002; Sallam et al., 2002). Two studies demonstrated that cavity depth as noted by ultrasound at the time of embryo transfer differed from the cavity depth via office trial transfer by $\geq 1.0 \mathrm{~cm}$ in $\geq 30 \%$ of cases (Pope et al., 2004; Shamonki et al., 2005b). The main risk factor predicting a discrepancy between the perceived and actual uterine cavity length was a history of pregnancy, especially if the patient had a delivery (Shamonki et al., 2005b). Another far less likely theory explaining the discrepancy is that uterine length may be increased with exposure to estradiol. Research has demonstrated a positive correlation between estradiol exposure and uterine size (Adams et al, 1984; Gull et al., 2005). However, if $\sim 2$ weeks of high estradiol exposure significantly lengthened the uterus during an IVF cycle, one would expect a more uniform discrepancy between trial transfer and actual uterine cavity lengths in the majority of IVF patients, which is not the case. Physicians may argue that UGET has additional benefits over UTT other than the diagnosis of a trial transfer inaccuracy. The evidence from studies would imply that the addition of ultrasound guidance during trial transfer would further reduce the benefit of UGET when used routinely ( Diedrich et al., 1989; Englert et al., 1986; Ghazzawi et al., 1999; Goudas et al., 1998; Hearns-Stokes et al., 2000; Leeton et al., 1982; Wood et al., 1985).

Among the various aspects of embryo transfer, the site of embryo placement in the uterine cavity has been postulated to influence embryo implantation rates. Whereas some investigators believe that higher levels in the endometrial cavity closer to the uterine fundus lead to higher rates (Krampl et al., 1995; Meldrum et al., 1987 ), others have suggested that improved embryo transfer results are obtained when the embryos are placed at lower levels in the uterine cavity (Coroleu et al., 2002a; Frankfurteret al., 2003; Lesny et al., 1998; Naaktgeboren et al., 1997; Naaktgeboren et al., 1998; Van de Pas et al., 2003; Waterstone et al., 1991; Woolcott and Stanger, 1997;). Waterstone et al. (1991) reported the results of embryo transfer performed by two clinicians who followed different techniques. The first introduced the catheter until he felt the fundus and then pulled it back $5 \mathrm{~mm}$ before injecting the embryos, and achieved a final pregnancy rate of $24 \%$. The second clinician introduced the catheter until a depth of $5 \mathrm{~cm}$ from the external orifice of the cervix and deposited the embryos without touching the fundus, and obtained a pregnancy rate of $46 \%$. When the first clinician modified his technique according to that of the second, improvement in pregnancy rates was observed. Coroleu et al. (2002) demonstrated in a prospective randomized trial of women undergoing UGET that the pregnancy rate was significantly higher when the 
embryos were transferred at $1.5-2.0 \mathrm{~cm}$ instead of at $1.0 \mathrm{~cm}$ from the uterine fundus. Frankfurter et al. (2003) retrospectively analyzed 23 patients who underwent two cycles of ultrasound-guided embryo transfer each, considering for each patient a transfer that resulted in pregnancy and one that did not. The results showed better pregnancy rates when the site of embryo placement relative to the length of the endometrial cavity was more distant from the uterine fundus. No significant difference was observed when comparing the absolute distance.

In our study 106 patients underwent a standard down regulation protocol for ovarian stimulation in IVf cycles. Embryo transfer took place 2-4 days after oocyte retrieval. The patients were grouped according to the distance between the tip of the catheter and the uterine fundus at transfer: group $1: 10 \pm 2.5 \mathrm{~mm}$; group 2: $15 \pm 2.5 \mathrm{~mm}$ Patients were selected on the basis of the following inclusion criteria; main causes of infertility was tubal, ovaria, idiopatic or male factor and normal uterine cavity confirmed by ultrasound or hysterosalpingography. There were no differences in age, number of days of ovarian stimulation, total number of oocyte retrieved, and number of good quality embryos between these groups of patients. There was statistically significantly difference in pregnancy rate (group $1=28,8$ and group $2=46,2 \%$ ) respectively, with $(\mathrm{P}<0.05)$. Our results suggest that depth of embryo replacement inside the uterine cavity may influence the implantation rates and should be considered as an important factor to improve the success of IVF cycles.

One study retrospectively demonstrated that for every additional millimeter embryos are deposited away from the fundus, as noted by abdominal ultrasound, the odds of clinical pregnancy increased by $11 \%$ (Pope et al., 2004). However, not all studies show an association between embryo transfer location and outcome (Rosenlund et al., 1996). In addition, others demonstrate that the best site for embryo transfer is the center of the uterine cavity, and that the relative site of embryo deposition is more important than the actual distance from the fundus (Franco et al., 2004; Oliveira et al., 2004). Finally, some authors postulate that the question regarding the site of embryo transfer does is of no importance since it does not influence implantation as long as embryos are placed in the upper half of the cavity (Nazari et al., 1993; Roselund et al., 1996).

Various studies have suggested implantation in locations ranging from the lower uterine segment, to various distances $(0.5 \mathrm{~cm}-2.0 \mathrm{~cm})$ from the uterine fundus. However, these distances still only represent generalized locations. Furthermore, the value to place on these distances as guidelines decreases when considering that the configuration and dimensions of the uterine cavity vary between women. The location of embryo transfer in respect to the uterine anatomy also varies among physicians.

Two dimensional sonography has still only provided guidance as to the general area at which the embryo should be released for implantation. 3D sonography can improve visualization of the uterus in patients with normal anatomy and especially in those with congenital uterine anomalies. Thus, the present invention provides a maximal implantation potential (MIP) point as a target for embryo transfers.

The uterine cavity resembles an inverted triangle and the fallopian tubes open into the cavity, one in each of the upper regions of the triangle. The MIP is the intersection of these two imaginary lines, one originating in each fallopian tube, within the inverted triangle. In 
natural pregnancies, fertilization usually occurs in the ampullary segment of the fallopian tube and the pre-embryo then travels down to the uterus and usually implants in the anterior or posterior segment of the uterus close to its trajectory line, where the endometrium is the thickest and has the greatest blood flow. In patients undergoing IVF, the fallopian tubes are bypassed, placing the embryos directly into the uterus (Gergely et al., 2005).

Liedholm et al. (1980) placed small spheres in a column containing $50 \mu \mathrm{l}$ of fluid and performed a simulated embryo transfer immediately before hysterectomy. The uterine cavity was then inspected and the microspheres were found within a distance of $1 \mathrm{~cm}$ from the presumed deposition site. These results emphasize the importance of the site where the embryos were transferred. Baba et al. (2000) analyzed 60 embryo transfers that resulted in 22 pregnancies and 32 gestational sacs. Twenty-six of the 32 sacs were detected by threedimensional ultrasound in the area where the air bubble had been observed immediately after transfer.

From early work on surgically removed uteri of Adams et al. (1956) implantation was found to take place in the upper half of the uterine cavity, most on the posterior wall of the uterus. This further supports the MIP point as an advantageous spot, mimicking implantation in the general population. Since 3D/4D ultrasonography allows us to identify the MIP point with great ease, it is now possible to use the combination of MIP and 3D/4D sonography to accomplish embryo transfers accurately. Thus, the Maximal Implantation Potential Point can be readily identified and individualized for each patient. By using the MIP point, placement of the embryos occurs where nature intended. Because of individual anatomic differences, the MIP point can be individually tailored. Further advances in 3D ultrasonography as well as the introduction of $4 \mathrm{D}$ sonography have enabled us to visualize the transfer catheter in real time as it moves towards its target, the MIP point. Embryo transfers at the MIP were associated with good implantation and pregnancy rates (Gergely et al., 2005).

It is not fully understood why the pregnancy rate is higher with the transfer of embryos lower in the uterine cavity. One theory suggests that catheter contact with the uterine fundus may be avoided when embryos are transferred to the lower part of the uterine cavity. Strong fundouterine contractions can result from fundal contact (Fanchin et al., 1998; Lesny et al., 1998), which may have a negative impact on pregnancy rates (Lesny et al., 1999). It is inevitable that insertion of the catheter- after all a foreign body- may interfere with normal uterine peristalsis. Embryos often relocate from the uterine cavity after IVF/ET. They have been found in the vagina (Poindexter et al., 1986; Schulman et al., 1986) and there is a high ectopic pregnancy rate, raging from 2.1\% (Azem et al., 1993) to 9.4\% (Zouves et al., 1991) after assisted conception treatment. It is worth remembering that the very first pregnancy conceived after IVF/ET was an ectopic gestation in the fallopian tube (Steptoe and Edwards, 1976). The evidence that this relocation is the consequence of junctional zone contractions is considerable. Experimental studies of mock ET in humans have demonstrated the expulsion of methylene blue in $57 \%$ of transfers (Mansouret al., 1994) and the movement of X-ray contrast medium towards the fallopian tubes and cervix/vagina in $38 \%$ and $21 \%$, respectively (Knutzen et al., 1992). In observations of junctional zone contractions after easy and difficult mock ETs,(Lesny et al., 1998) use of different catheters,(63) application of a tenaculum to the cervix (lesny et al., 1999a) or stimulation of contractions after transmyometrial ET (Biervliet et al., 2002; Lesny et al., $1999 \mathrm{~b}$ ) all report increased contractions following increasing trauma at the time of ET. Using 
mock ET in oocyte donor patients as a model, it was shown that even minimal stimulation such as touching the uterine fundus with the soft end of the ET catheter is capable of generating evident contractions, which can relocate mock embryos (a bolus of the echogenic substance Echovist) from the upper part of the uterine cavity towards the cervix or into the fallopian tubes.

There are only limited data from studies concerning the speed of withdrawal of the catheter. Some authors have suggested that it is preferable to wait before retiring the catheter so that the uterus can become stabilized (Wisanto et al., 1989), whereas others report good results withdrawing the catheter immediately after an easy transfer (Zech et al., 1997). No differences were observed in the pregnancy rate between withdrawals of the catheter immediately after embryo deposit or after a $30 \mathrm{~s}$ wait in a population of women with good response to stimulation and "easy" US- guided embryo transfer on at least two optimal embryos (Martinez et al., 2001).

Various catheter types exist. They can be rigid or soft, with or without outer catheter, with or without metal sound catheter, with or without "memory". Coroleu et al. (2006) In a pilot study suggested that the use of the echogenic Wallace catheter simplifies ultrasound-guided embryo transfer as it facilitates catheter identification under ultrasound, and thus the duration of the embryo transfer procedure was significantly shorter in the echogenic catheter group as compared with the standard catheter group. However, they could not find a definite benefit in terms of pregnancy rates. In contrast, the use of the new catheter was associated with a significant increase in the number of twin pregnancies.

Several randomized and non-randomized studies have been performed to compare different brands of catheters (Mansour et al., 1990; Gonen et al., 1991; Wisanto et al., 1989). Soft catheters seem to lead to superior results, but insertion can be more difficult. Furthermore, the use of a soft catheter instead of a rigid one may cause less endometrial trauma and has been shown to improve outcome (Wood et al., 2000).

Four of the randomized controlled trials (Garcia-Velasco et al., 2002; Matorras et al., 2002; Sallam et al., 2002; Tang et al., 2001; ) reported more ectopic pregnancies in the blind group than in the ultrasound-assisted ET group. Three randomized controlled trials did not mention ectopic pregnancies. One study retrospectively demonstrated that ectopic pregnancies occurred significantly less frequently when the embryos were placed away from the fundus (Pope et al., 2004).

The main disadvantages of using ultrasound guidance during embryo transfer is patient discomfort due to a full bladder. Some authors claim that a full bladder, required for UGET, can make the embryo transfer easier because this reduces the angle at the cervico-uterine junction and straightens the uterine cavity in relation to the cervical canal (Sharif et al., 1995; Sundstrom et al., 1984; Wood et al., 2000). When comparing a full bladder without the use of ultrasound during embryo transfer, some data have shown a benefit (Lewin et al., 1997) while others have not (Mitchell et al., 1989). In their study Lorusso et al., (2005); Kosmas et al. (2007) shows that high overall pregnancy rates can be achieved when ETs are performed in patients with an empty bladder, whether they are performed under ultrasound guidance or not. Also, studies that utilize transvaginal ultrasound, requiring an empty bladder during embryo transfer, show an improvement in the pregnancy rate (Anderson et al., 2002; Kojima 
et al., 2001; Lindheim et al., 1999) suggesting that a full bladder required for UGET is not a confounder for improving outcome.

The majority of the published studies were done with abdominal ultrasound.. The value of abdominal ultrasound in addition of visualizing the catheter is to straighten the uterovesical angle which my make the insertion of the catheter easier (Sallam et al., 2000). Kojima et al. (2001) tried to use vaginal ultrasound as it allows visualization of the tip of the catheter precisely and concluded that it increases the pregnancy and implantation rate; in the same time they admitted that it technically more difficult. The procedure did not gain popularity because of its discomfort to the patient. Isobe et al. (2003) compared the transrectal approach in retroflexed uterus and found that it increases the incidence of easier transfer and pregnancy rate; however, there was no comment on the acceptance of the procedure.

We believe that gentle and atraumatic ET is the simplest and cheapest way to improve disappointing pregnancy rates. In our routine clinical practice ET is performed by : transabdominal ultrasound guided with full bladder; with soft catheters; not touching the uterine fundus - distance between the tip of the catheter and the uterine fundus $>1.5 \mathrm{~cm}$; not using a tenaculum; utilizing a mock ET...

\subsection{Conclusion}

Of all factors influencing the ET process, ultrasound guidance of the ET has been studied the most over the past decade. Issues related to the ET technique, ET provider/physician, transferred embryos and unloading site in the uterus and their relationship to ultrasound guidance were the most debatable aspects of the process.

In summary, the reports regarding the effect of guiding the transferred embryo deposition by ultrasound are conflicting. Some showing an improvement in outcome (Al-Shawaf et al., 1993; Baba et al., 2000; Ivanovski et al., 2006; Kan et al., 1999; Kojima et al., 2001;Woolcott et al., 1998 ), others demonstrating no difference (Coroleu et al., 2002; De Camargo et al., 2004; Garcia-Velasco et al., 2002; Li et al., 2005; Lindheim et al., 1999; Mirkin et al., 2003; Prapas et al., 1995 ) and others with mixed results (Fisser et al., 2006; Hurley et al., 1991; Prapas et al., 2001). No study has shown a worsening of outcome when ultrasonography is used.

Compared with the traditional method, abdominal ultrasound-guided embryo transfer has a number of potential benefits (Hearns-Stokes et al., 2000; Leeton et al., 1982; Nabi et al., 1997; Sallam et al., 2002). First, with the guidance of ultrasound, the catheter can be bent to easily pass through the cervical canal and follow the uterine axis, which helps avoid overstimulation and reduction in incidence of difficult transfers, endometrial trauma (Letterie et al., 1999; Woolcott and Stanger, 1997), and bleeding (Goudas et al., 1998; Nabi et al., 1997; Sallam et al., 2002) that can cause excessive fundo-uterine contractions (Lesny et al., 1999) at the time of embryo transfer has been associated with lower clinical pregnancy rates (Goudas et al., 1998; Sallam et al., 2002). Second, the entire process of catheterization and release of the embryos can be visualized, making it easier to place the embryos in the correct position within the uterus (Woolcott and Stanger, 1997) and decrease the chance of improper embryo placement (Coroleu et al., 2002; Pope et al., 2004; Rosenlund et al., 1996; Shamonki et al., 2005; Woolcott and Stanger, 1997). The 3D US allows viewing the catheter 
tip in a frontal as well as a sagittal and transverse plans, thus it facilitates precise embryo placement inside the uterus. In addition, the full bladder required for transabdominal ultrasound itself is useful for the correction of uterine access through the cervical route in cases of pronounced anteversion-anteflexion. Because of individual anatomic differences the maximal implantation potential point should be readily identified and individualized for each patient.

In particular, the main disadvantages of using ultrasound guidance during embryo transfer may be the additional time and personnel required, as well as patient discomfort due to a full bladder and the urge to urinate (Bucket et al., 2003)

\section{References}

Achiron R, Levran D, Sivan E, Lipitz S, Dor J, Mashiach S. (1995) Endometrial blood flow response to hormone replacement therapy in women with premature ovarian failure: a transvaginal Doppler study. Fertile steril; 63;550-4

Adams EC, Hertig AT, Rock J. (1956) A description of 34 human ova within the first 17 days of development. Am J Anat; 98:435-93.

Adams J, Mason WP, Tucker M, Morris DV and Jacobs HS (1984) Ultrasound assessment of changes in the ovary and the uterus during LHRH therapy. Upsala J Med Sci89,3942.

Agrawal R, Conway GS, Sladikevicius p, payne NN, Bekir J, Campbell S et al. (1999) Serum vascular endothelial growth factor (VEGF) in the normal menstrual cycle: association with changes in ovarian and uterine Doppler blood flow. Clin Endocrinol 9Oxf); 50:101-6

Alcázar, JL. (2006) Three-dimensional ultrasound assessment of endometrial receptivity: a review. Reproductive Biology and Endocrinology; 4:56-59

Alcázar JL, Mercé LT, García-Manero M, Bau S, López-García G: (2005) Endometrial volume and vascularity measurements by transvaginal three-dimensional ultrasonography and power Doppler angiography in stimulated and tumoral endometria: an interobserver reproducibility study. J Ultrasound Med, 24:1091-1098.

Al-Shawaf T, Yang D, al-Magid Y, Seaton A, Iketubosin F, Craft I (1993). Ultrasonic monitoring during replacement of frozen/thawed embryos in natural and hormone replacement cycles. Hum Reprod;8:2068-74.

Amir W, Micha B, Ariel H, Liat LG, Jehoshua D, Adrian S. (2007) Predicting factors for endometrial thickness during treatment with assisted reproductive technology. Fertil Steril; 4: 799- 804.

Anderson RE, Nugent NL, Gregg AT, Nunn SL and Behr BR (2002) Transvaginal ultrasound-guided embryo transfer improves outcome in patients with previous failed in vitro fertilization cycles. Fertil Steril77,769-775.

Applebaum M. (1995) The Menstrual Cycle, menopause, Ovulation Induction, an In Vitro fertilization. In: Copel JA, reed KL ( Eds): Doppler Ultrasound in Obsterics and Gynecology. New York: raven Press,; 71-86

Applebaum M. (1995) The uterine biophysical profile. Ultrasound Obstet Gynecol;5:67-8. 
Azem F, Yaron Y, Botchan A (1993). Ectopic pregnancy after in vitro fertilization -embryo transfer (IVF/ET): the possible role of the ET technique. J Assist Reprod Genet;10:302- 304.

Baba K, ishiara O, hayashi N, saitoh M, Taya j, Kinoshita K. (2000) Where does the embryo implant after embryo transfer in humans. Fertil steril; 73:123-5

Baba K, Ishihara O, Hayashi N, Saitoh M, Taya J, Kinoshita K. (2000) Three-dimensional ultrasound in embryo transfer. Ultrasound Obstet Gynecol;16:372-3.

Bakos O, Lundvist O, Bergh T. (1993) Transvaginal sonographic evaluation of endometrial growth and texture in spontaneous ovulatory cycles - a descriptive study. Hum Reprod; 8: 799-806

Bassil S. (2001) Changes in endometrial thickness, width, length and pattern in predicting pregnancy outcome during ovarian stimulation in in vitro fertilization. Ultrasound Obstet Gynecol; 18:258-63

Battaglia C, Artini PG, Giulini S, salvatori M, maxia N, Petraglia F et al. (1997) Color Doppler changes and tromboxane production after ovarian stimulation with gonadotrophin-releasing hormone agonist. Hum Reprod; 11:2477-82.

Biervliet FP, Lesny P, Maguiness SD, Robinson J, Killick SR (2002). Transmyometrial embryo transfer and junctional zone contractions. Hum Reprod;17:347- 350.

Blumenfeld Z, Dirnfeld M, Beck H. (1990). Comparasion of treatment of uterine leiomyomata with three GnRH agonistic analogues - efficacy and side-effects. In Vickery B and Lunenfield B (eds.) GnRH Analogues in cancer and Human Reproduction; Vol.3 : 45 (boston: Kluwer Academic Publishers)

Bordes A, Bory AM, Benchaib M, Rudigoz RC, Salle B: (2002) Reproducibility of transvaginal three-dimensional endometrial volume measurements with virtual organ computer-aided analysis (VOCAL) during ovarian stimulation. Ultrasound Obstet Gynecol, 19:76-80.

Bourne TH, Hagstrom HG, Granberg S, Josefsson B, hahlin M, Hellberg P, et all. (1996) Ultrasound studies of vascular and morphological changes in the human uterus after a positive self-test for the urinary luteinizing hormone surge. Hum Reprod; 11:369-5

Buckett WM (2003) A meta-analysis of ultrasound-guided versus clinical touch embryo transfer. Fertil Steril 80, 1037-1041.

Cacciatore, B., Tiitinen, A. and Yhkorkala, O. (1996). Is it possible to improve uterine blood flow in infertile women? [Abstract]; Ultrasound Obstet. Gynecol, 8(Suppl.l), 204

Caccitore B, Simberg N, Fusaro P, Titinen A. (1996) Transvaginal Doppler study of uterine artery blood flow in in-vitro fertilization - embryo transfer cycles. Fertile Steril; 66: $130-4$

Check JH, Dietterich C, Lurie D. (2000) Non-homogenous hyperechogenic pattern 3 days after embryo transfer is associated with lower pregnancy rates. Hum Reprod; 15:1096-74.

Check JH, Gandica R, Dietterich C, Lurie D. (2003) Evaluation of a nonhomogeneous endometrial echo pattern in the midluteal phase as a potential factor associated with unexplained infertility. Fertil steril; 79:590-3 
Chien LW, Au HK, Chen PL, Xiao J, CR. (2002) Assessment of uterine receptivity by the endometrial-subendometrial blood flow distribution pattern in women undergoing in vitro fertilization-embryo transfer. Fertil Steril; 78:245-251.

Coroleu B, Barri P, Carreras O, Belil I, Buxaderas R, Veiga A, and BalaschJ. (2006) Effect of using an echogenic catheter for ultrasound-guided embryo transfer in an IVF programme: a prospective, randomized, controlled study Hum Reprod; 21: 1809 1815.

Coroleu B, Barri PN, Carreras O, Martinez F, Parriego M, Hereter L, Parera N, Veiga A and Balasch J (2002) The influence of the depth of embryo replacement into the uterine cavity on implantation rates after IVF: a controlled, ultrasound-guided study. Hum Reprod17,341-346.

Coroleu B, Barri PN, Carreras O, Martínez F, Veiga A, Balasch J. (2002) The usefulness of ultrasound guidance in frozen-thawed embryo transfer: a prospective randomized clinical trial. Hum Reprod;17:2885-90.

Coroleu B, Carreras O, Veiga A, Martell A, Martinez F, Belil I, Hereter L and Barri PN (2000) Embryo transfer under ultrasound guidance improves pregnancy rates after invitro fertilization. Hum Reprod15,616-620.

De Camargo Martins AMV, Baruffi RLR, Mauri AL, Peteresen C, Oliveira JBA, Contart P, et al. (2004) Ultrasound guidance is not necessary during easy transfers. J Assist Reprod Genet;21:421-5.

De Ziegler D, Fanchin R.( 1994) Endometrial receptivity in controlled ovarian hyperstimulation $(\mathrm{COH})$ : the hormonal factor. In: Bulletti C, Gurpide E, Flagmini C, (eds): the Human Endometrium. Ann n Y Acad Sci; 734: 209-20.

Dechaund H, bessueille E, Bousquet PJ, Reyftman L, Hamamah S, Hedon B (2008). Optimal timing of ultrasonographic and Doppler evaluation of uterine receptivity to implantation. Reprod Biomed Online; 16:368-375.

Demir R, Kayisli UA, Cayli S, Hupperzt B: (2006) Sequential steps during vasculogenesis and angiogenesis in the very early human placenta. Placenta, 27:535-539.

Dickey, R. P., Olar, T. T., Curole, D. N., Taylor, S. N. and Rye, P. H. (1992). Endometrial pat-tern and thickness associated with pregnancy outcome after assisted reproduction technolo-gies. Hum. Reprod.; 7, 418-21

DiedrichK, Van der Ven H, Al-Hasani S and Krebs D (1989) Establishment of pregnancy related to embryo transfer techniques after in-vitro fertilization. Hum Reprod4,111114.

Dietterich C, Check JH, Choe JK, Nazari A, Lurie D. (2002) Increased endometrial thickness on the day of human chronic gonadotrophin injection does not adversely affect pregnancy or implantation ratios following in vitro fertilization-embryo transfer. Fertil Steril; 4: 781-6.

Edwards RG. (1995). Clinical approaches to increasing uterine receptivity during human implantation. Hum Reprod;10(Suppl 2):60-6.

EnglertY, Puissant F, Camus M, Van Hoeck J and Leroy F (1986) Clinical study on embryo transfer after human in vitro fertilization. J in Vitro Fertil Embryo Transfer3,243246. 
Fanchin R, Righini C, Ayoubi JM, Olivennes F, de Ziegler D, Frydman R. (2000) New look at endometrial echogenicity: objective computer-assisted measurements predict endometrial receptivity in in vitro fertilization-embryo transfer. Fertil Steril; 2: 27481.

Fanchin R. (2001) Assessing uterine receptivity in 2001. Ultrasonographic glances at the New Millennium. An N Y Acad Sci; 943;185-202

Fanchin, R., Righini, C., Olivennes, F., Taylor, S., Ziegler de, D. and Frydman, R. (1998) Uterine contractions at the time of embryo transfer alter pregnancy rates after invitro fertilization. Hum. Reprod., 13, 1986-1974.

Fischer B, bavister BD. (1993) Oxygen tension in the oviduct and uterus of rhesus monkeys, hamsters and rabbits. J Reprod Fertil; 99:673-9.

Fleischer, A. C, Herbert, C. M., Sacks, G. A, YVentz, A. C, Entman, S. S. and James, A. E. Jr (1986). Sonography of the endometrium during conception and nonconception cycles of in vitro fertilization and embryo transfer. Fertil. Steril; 46, 442-7

Fleischer, A. C, Herbert, C. M., Sacks, G. A., Wentz, A. C. and Entman, S. S. (1986) Nonconception cvcles of IVF-ET. Fertil. Steril; 46, 442-6

Fleischer, A.C., Herbert, C.M., Hill, G.A. et al. (1991) Transvaginal sonography of the endometrium during induced cycles. J. Ultrasound Med; 10, 93-95.

Flisser E, Grifo JA, Krey LC, Noyes N. (2006) Transabdominal ultrasound-assisted embryo transfer and pregnancy outcome. Fertil Steril;85:353-7.

Forrest, T. S., Elvaderani, M. K., Muilenburg, M. I., Bewtra, C, Kable, W. T. and Sullivan, P. (1988) Cyclic endometrial changes: ultrasound assessment with histologic correlation. Radiol-ogy; 167, 233-7

Franco JG Jr, Martins AM, Baruffi RL, Mauri AL, Petersen CG, Felipe V, Contart P,Pontes A, Oliveira JB. (2004) Best site for embryo transfer: the upper or lower half of endometrial cavity? Hum Reprod ;19:1785-1790.

Frankfurter D, Silva CP, Mota F, Trimarchi JB and Keefe D (2003) The transfer point is a novel measure of embryo placement. Fertil Steril 79, 1416-1421

Frankfurter D, Trimachi J, Silva C, Keefe D. (2004) Middle to lower uterine segment embryo transfer improves implantation and pregnancy rates compared with fundal embryo transfer. Fertil Steril; 81:1273-7.

Freidler, S., Schenker, J. G., Herman, A. and Lewin, A. (1996) The role of ultrasonographv in the evaluation of endometrial receptivity fol-lowing assisted reproductive treatments: a crit-ical review. Hum. Reprod. Update; 2, 323-35

Fujiwara T, Togashi K, Yamaoka T, Nakai A, Kido A, Nishio S, yamamoto T, Kitagaki H, Fujii S (2004). Kinematiks of the uterus: Cine mode MR Imaging. Radiographics; 24: 19-26

Garcia-Velasco JA, Isaza V, Martinez-Salazar J, Landazabal A, Requena A, Remohi J and Simon C (2002) Transabdominal ultrasound-guided embryo transfer does not increase pregnancy rates in oocyte recipients. Fertil Steril 78,534-539.

Gergely RZ, DeUgarte CM, Danzer H, Surrey M, Hill D, DeCherney AH.(2005) Three dimensional/four dimensional ultrasoundguided embryo transfer using the maximal implantation potential point. Fertility and Sterility 84: 500-503). 
GhazzawiIM, Al-Hasani S, Karaki R and Souso S (1999) Transfer technique and catheter choice influence the incidence of transcervical embryo expulsion and the outcome of IVF. Hum Reprod14,677-682.

Glissant, A., de Mouzon, J. and Frydman, R. (1985) Ultrasound study of the endometrium during in vitro fertilization cycles. Fertil. Steril; 44, 786-90

Goldberg BB, Liu JB, Kuhlman K, Merton DA, Kurtz AB.(1991). Endoluminal gynecologic ultrasound: preliminary results. J Ultrasound Med; 10: 583-90

Gonen, Y., Casper, R. F., Jacobson, W. and Blankier, J. (1989). Endometrial thickness and growth during ovarian stimulation: a possible predictor of implantation in in vitro fertiliza-tion. Fertil. Steril, 52, 446-50

Gonen, Y., Dirnfeld, M., Goldman, S., Koifman, M. and Abramovici, H. (1991) Does the choice of catheter for embryo transfer influence the success rate of in-vitro fertilization? Hum. Reprod., 6, 1092-1094.

Goswamy RK, Williams G, Steptoe PC. (1988) Decreased uterine perfusion-a cause of infertility. Hum Reprod; 3:955-9.

Goudas, V.T., Hammitt, D.G., Damario, M.A., Session, D.R., Singh, A.P. and Dumesic, D.A. (1998) Blood on the embryo transfer catheter is associated with decreased rates of embryo implantation and clinical pregnancy with the use of in vitro fertilizationembryo transfer. Fertil. Steril., 70, 878-882.

Gull B, Karlsson B, Milsom I and Granberg S (2001) Factors associated with endometrial thickness and uterine size in a random sample of postmenopausal women.Am J Obstet Gynecol,185,386-391.

Hauksson A, Akerlund M, Melin P. (1988) Uterine blood flow and myometrial activity at menstruation, and the action of vasopressin and a synthetic antagonist. Br J Obstet Gynecol; 95:898-904.

Hearns-Stokes, R.M., Miller, T.B., Scott, L., Creuss, D., Chakraborty, P.K. and Segars, J.H. (2000) Pregnancy rates after embryo transfer depend on the provider at embryo transfer. Fertil. Steril., 74, 80-86.

Hurley VA, Osborn JC, Leoni MA, Leeton J. (1991) Ultrasound-guided embryo transfer: a controlled trial. Fertil Steril;55:559-62.

Isobe T, Minoura H, Kawato H and Toyoda N. (2003) Validity of trans-rectal ultrasoundguided embryo transfer against retroflexed uterus Reprod Med Biol; 2: 159-163.

Ivanovski M, Lazarevski S, Popovic M et al. (September 2004). Assessment of endometrial receptivity by transvaginal Color Doppler in women undergoing IVF-ET procedures. 1-st Balkan Congress of reproductive Medicine. Thessaloniki, Greece. Book of Abstracts ; p 2.

Ivanovski M, lazarevski S, Popovic M et al.(2007b). Comparison of blood flow measured by Doppler ultrasound between natural and stimulated ovulatory cycles in in vitro fertilization and embryo transfer program. VOX Medici; 57:28-31

Ivanovski M, lazarevski S, Popovik M et al.(2007a). Assessment of endometrial thickness and pattern in prediction of pregnancy in an in vitro fertilization an embryo transfer cycles after ovarian stimulation. Macedonian medical review; 4-6:117-124 
Ivanovski M. (November 2006). Comparison of ultrasound guided embryo transfer and previous failed blind embryo transfer in IVF cycles. XVIII FIGO World Congress of Gynecology and Obstetrics; Kuala Lumpur, Malaysia; Book of abstracts: 160.

Jarvela IY, Sladkevicius P, Kelly S, Ojha K, Campbell S, Nargund G: (2005) Evaluation of endometrial receptivity during in-vitro fertilization using three-dimensional power Doppler ultrasound. Ultrasound Obstet Gynecol, 26:765-769.

Jarvela IY, Sladkevicius P, Tekay AH, Campbell S, Nargund G: (2003) Intraobserver and interobserver variability of ovarian volume, gray-scale and color flow indices obtained using transvaginal three-dimensional power Doppler ultrasonography. Ultrasound Obstet Gynecol, 21:277-282.

Jokubkiene L, Sladkevicius P, rovas L, Valentin L. (2006) Assessment of changes in endometrial and subendometrial volume and vascularity during the normal menstrual cycle using three-dimensional power Doppler ultrasound. Ultrasound Obstet Gynecol; 27: 672-9.

Jurkovic D, Geipel A, Gruboeck K, Jauniaux E, Natucci M, Campbell S. (1995) Threedimensional ultrasound for the assessment of uterine anatomy and detection of congenital anomalies: a comparison with hysterosalpingography and twodimensional sonography. Ultrasound Obstet Gynecol; 5 (4):233-7.

Kan AK, Abdalla HI, Gafar AH, Nappi L, Ogunyemi BO, Thomas A, et al (1999). Embryo transfer: ultrasound-guided versus clinical touch. Hum Reprod;14:1259-61.

Karande, V.C., Morris, R., Chapman, C., Rinehart, J. and Gleicher, N. (1999) Impact of the "physician factor" on pregnancy rates in a large assisted reproductive technology program: do too many cooks spoil the broth? Fertil. Steril., 71, 1001-1009.

Kepic, T, Applebaum, M. and Valle, J. (1992) Preovulatory follicular size, endometrial appearance, and estradiol levels in both con-ception and non-conception cycles: a retro-spective study. Presented at the 40th Annual Clinical Meeting of the American College of Obste-tricians and Gynecologists, April; Abstr. 20

Khalifa, E., Brzvski, R. G., Oehninger, S., Acosta, A. A. and Muasher, S.J. (1992) Sono-graphic appearance of the endometrium: the predictive value for the outcome of in vitro fertilization in stimulated cycles. Hum. Reprod.; 7, 677-80

Killick SR (2007). Ultrasound and receptivity of the endometrium. Reproductive BioMedicine Online: www.rbmonline.com/Article/2859; Vol 15 Mo 1; 63-67

Knutzen V, Stratton CJ, Sher G, McNamee PI, Huang TT, Soto- Albors C (1992). Mock embryo transfer in early luteal phase, the cycle before in vitro fertilization and embryo transfer a descriptive study. Fertil Steril;57:156- 162.

Kojima K, Nomiyama M, Kumamoto T, Matsumoto Y and Iwasaka T (2001) Transvaginal ultrasound-guided embryo transfer improves pregnancy and implantation rates after IVF. Hum Reprod16,2578-2582.

Kosmas IP, Janssens R, De Munck L, Al Turki H, Van der Elst J, Tournaye H. (2007) Ultrasound-guided embryo transfer does not offer any benefit in clinical outcome: a randomized controlled trial. Hum Reprod ; 22:1327-1334.

Krampl E, Zegermacher G, Eichler C, Obruca A, Strohmer H and Feichtinger W (1995) Air in the uterine cavity after embryo transfer. Fertil Steril 63, 366-370. 
Krampl, E. and Feichtinger, W. (1993). Endo-metrial thickness and echo patterns [Letter]. Hum. Reprod., 8, 1339

Kunz G, Beil D, Deininger H, Wildt L, Leyendecker G. The dynamics of rapid sperm transport through the female genital track: evidence from vaginal sonography of uterine peristalsis and hysterosalpingoscintigraphy. Hum Reprod 1996;11:627- 632.

Kupesic S, Bekavac I, Bjelos D, Kurjak A. (2001) Assessment of endometrial receptivity by transvaginal color Doppler and three-dimensional power Doppler ultrasonography in patients undergoing in vitro fertilization procedures. J Ultrasound Med;20:12534.

Kupesik S, Merce LT, Zodan T, Kurjak A. (2000) Normal and abnormal corpus luteum function. In Kupesic S, de Ziegler D, (Eds.): Ultrasound and Infertility. Lancs: The Parthenon Publishing Group,; 67-76.

Kyei-Mensah A, Maconochie N, Zaidi J, Pittrof R, Campbell S, Tan SL: (1996) Transvaginal three-dimensional ultrasound: reproducibility of ovarian and endometrial volume measurements. Fertil Steril, 66:718-722.

Lee A, Sator M, Kratochwil A, Deutinger J, Vytiska- Binsdorfer E, Bernaschek G. (1997) Endometrial volume change during spontaneous menstrual cycles: volumetry by transvaginal three-dimensional ultrasound. Fertil Steril; 68(5): 831-5.

Leeton J, Trounson A, Jessop D and Wood C (1982) The technique for human embryo transfer. Fertil Steril38,156-161.

Leibovitz Z, Grinin V, Rabia R, Degani S, Shapiro I, Tal J et al. (1999) Asseessement of endometrial receptivity for gestation in patients undergoing in vitro fertilization, using endometrial thickness and the endometrium-myometrium relative echogenicity coefficient. Ultrasound Obstet Gynecol; 14:194-9.

Leong M, Leung C, Tucker M, Wong C and Chan H (1986) Ultrasound-assisted embryo transfer. J in Vitro Fertil Embryo Transfer3,383-385.

Lesny P, Killick SR, Robinson J, Raven G, Maguiness SD (1999a). Embryo transfer and junctional zone contractions: is it safe to use a tenaculum? Hum Reprod; 14:23672370.

Lesny P, Killick SR, Robinson J, Titterington J, Maguiness SD (1999). Case report: ectopic pregnancy after transmyometrial embryo transfer. Fertil Steril;72:357 -359.

Lesny P, Killick SR, Tetlow RL, Manton DJ, Robinson J, Maguiness SD. (1999) Ultrasound evaluation of the uterine zonal anatomy during in-vitro fertilization and embryo transfer. Hum Reprod;14:1593-8.

Lesny P, Killick SR, Tetlow RL, Robinson J and Maguiness SD (1998) Embryo transfer - can we learn anything new from the observation of junctional zone contractions? Hum Reprod 13, 1540-1546.

Lesny P, Killick SR, Tetlow RL, Robinson J and Maguiness SD (1999) Embryo transfer and uterine junctional zone contractions. Hum Reprod Update5,87-88.

Lesny, P.L., Killick, S.R., Robinson, J. et al. (1999) Junctional zone contractions and embryo transfer: is it safe to use a tenaculum?. Hum. Reprod., 14, 2367-2370. 
Letterie GS, Marshall L and Angle M (1999) A new coaxial catheter system with an echodense tip for ultrasonographically guided embryo transfer. Fertil Steril72,266268.

Levi Setti PE, Albani E, Cavagna M, Bulletti C, Colombo GV and Negri L (2003) The impact of embryo transfer on implantation - a review. Placenta 24 (Suppl B), 20-26.

Lev-Toaff AS, Pinheiro LW, Bega G, Kurtz AB, Goldberg BB. (2001) Three-dimensional multiplanar sonohysterography: comparison with conventional twodimensional sonohysterography and X-ray hysterosalpingography. J Ultrasound Med; 20(4): 295-306.

Lewin A, Schenker JG, Avrech O, Shapira S, Safran A and Friedler S (1997) The role of uterine straightening by passive bladder distension before embryo transfer in IVF cycles. J Assist Reprod Genet14,32-34.

Li R, Lu L, Hao G, Zhong K, Cai Z, Wang W. (2005) Abdominal ultrasound-guided embryo transfer improves clinical pregnancy rates after in vitro fertilization: experiences from 330 clinical investigations. J Assist Reprod Genet; 22:3-8.

Li, T. C, Nutlall, L., Klentzeris, L. and Cooke, I. D. (1992). How well does ultrasonographic measurement of endometrial thickness predict the results of histological dating? Hum. Reprod.. 7, 1-5

Liedholm P, Sundstrom P and Wramsby H (1980) A model for experimental studies on human egg transfer. Arch Androl 5,92

Lindheim SR, Cohen MA and Sauer MV (1999) Ultrasound guided embryo transfer significantly improves pregnancy rates in women undergoing oocyte donation. Int J Gynaecol Obstet66,281-284.

Li-Wei Chien, M.D., Heng-Kien Au, M.D., Ping-Ling Chen, Ph.D., c Jean Xiao, M.D. and Chii-Ruey Tzeng, M.D. (2002) Assessment of uterine receptivity by the endometrial-subendometrial blood flow distribution pattern in women undergoing in vitro fertilization-embryo transfer. Fertil Steril; 78:245-251.

Lorusso F, Depalo R, Bettocchi S, Vacca M, Vimercati A, Selvaggi L.( 2005) Outcome of in vitro fertilization after transabdominal ultrasound-assisted embryo transfer with a full or empty bladder. Fertil Steril ; 84:1046-104.

Mansour R, Aboulghar M, Serour G. (1990) Dummy embryo transfer: a technique that minimizes the problems of embryo transfer and improves the pregnancy rate in human in vitro fertilization. Fertil Steril. Oct; 54(4): 678-681.

Mansour RT and Aboulghar MA (2002) Optimizing the embryo transfer technique.Hum Reprod 17, 1149-1153.

Mansour RT, Aboulghar MA, Serour GI, Amin YM (1994). Dummy embryo transfer using methylene blue. Hum Reprod;9:1257-1259.

Mansour, R., Aboulghar, M. and Serour, G. (1990) Dummy embryo transfer: a technique that minimizes the problems of embryo transfer and improves the pregnancy rate in human in vitro fertilization. Fertil. Steril., 54, 678-681.

Martinez F, Coroleu B, Parriego M, Carreras O, Belil I, Parera N, Hereter L,Buxaderas R, Bar ri PN.(2001) Ultrasound-guided embryo transfer: immediate withdrawal of the catheter versus a 30 second wait. Hum Reprod ;16:871-874. 
Matorras R, Urquijo E, Mendoza R, Corcostegui B, Exposito A and Rodriguez-Escudero FJ (2002) Ultrasound-guided embryo transfer improves pregnancy rates and increases the frequency of easy transfers. Hum Reprod 17,1762-1766.

McCarthy S, Scott G, Majumdar S, Shapiro B, Thompson S, Lange R, et al. (1989) Uterine junctional zone: MR study of water content and relaxation properties. Radiology;171:241-3.

Meldrum DR, Chetkowski R, Steingold KA, de Ziegler D, Cedars MI and Hamilton M (1987) Evolution of a highly successful in vitro fertilization embryo transfer program.Fertil Steril 64, 382-389.

Merce LT, Moreno C, Bau S. (1995) Assessment of luteal and periimplantation blood flow with color Doppler in AIH. In; abstract Book of ESHRE Symposium on Reproductive Medicina. Valencia, 9-11 march,; 12.

Merce LT. (2000 ) Doppler de los cambios ovaricos y endometriales preimplantatiorios. En Kurjak A, carrera JM, ( Eds): Ecografia en Medicina Materno-Fetal. Barcelona: Masson; 87-104

Merce LT. (2000 ) studio Doppler de la implantacion y placentacion inicial. En Kurjak A, carrera JM, (Eds): Ecografia en Medicina Materno-Fetal. Barcelona: Masson,; 113-36.

Merce LT. Aplicationes del Doppler color en Reproduccion. (2002 ) IV Curso TeoricoPractico sobre Doppler en Ginecologia, Obstetrica y Ecocardiografia fetal. Barcelona, 2-4 de mayo,

Merce LT. Ultrasound markers of implantation. (2002). Ultrasound Rev Obstet Gynecol; 2:110-23

Merce LT. Ultrasound markers of implantation. In Kurjak A, Chervenak FA, (Eds.). (2004) Donald school Textbook of Ultrasound in Obsterics and Gynecology. New Delhi: Jaypee Brothers Medical Publishers,; pp 691-700

Merce TL, barco MJ, Bau S, Kurjak A (2008). Ultrasound Markers of implantation in Kurjak A, ChervenakFA (Eds): Donald School textbook of ultrasound in obstetrics and gynecology; New Delhi: JAYPEE Brothers Medical publishers LTD, 2008; 887-898.

Meriano, J., Weissman, A., Greenblaat, E.M., Ward, S. and Casper, R.F. (2000) The choice of embryo transfer catheter affects embryo implantation after IVF. Fertil. Steril.,74, 678-682.

Mirkin S, Jones EL, Mayer JF, Stadtmauer L, Gibbons WE and Oehninger S (2003) Impact of transabdominal ultrasound guidance on performance and outcome of transcervical uterine embryo transfer. J Assist Reprod Genet 20, 318-322.

Mitchell JD, Wardle PG, Foster PA and Hull MG (1989) Effect of bladder filling on embryo transfer. J in Vitro Fertil Embryo Transfer6,263-265.

Naaktgeboren N, Broers FC, Heijnsbroek I, Oudshoorn E, Verburg H and Van der Westerlaken L (1997) Hard to believe hardly discussed, nevertheless very important for the IVF/ICSI results: embryo transfer technique can double or halve the pregnancy rate.Hum Reprod 12 (Abstract Book 1), 149.

Naaktgeboren, N., Dieben, S., Heijnsbroek, I., Verburg, H. and Van der Westerlaken, L. (1998) Embryo transfer, easier said than done. Abstracts of the 16th World Congress on Fertility and Sterility and 54th Annual Meeting of the American Society for Reproductive Medicine, San Francisco, CA, USA, S352. 
Nabi A, Awonuga A, Birch H, Barlow S and Stewart B (1997) Multiple attempts at embryo transfer: does this affect in-vitro fertilization treatment outcome? Hum Reprod12,1188-1190.

Nardo LG: (2005) Vascular endothelial growth factor expression in the endometrium during the menstrual cycle, implantation window and early pregnancy. Curr Opin Obstet Gynecol, 17:419-423.

Nazari A, Askari HA, Check JH and O, Shaughnessy A (1993) Embryo transfer technique as a cause of ectopic pregnancy in in-vitro fertilization. Fertil Steril 60, 919-921.

Ng EH, Chan CC, Tang OS, Yeung WS, Ho PC (2005). Endometrial and subendometrial blood flow measured by three-dimensional power Doppler ultrasound in patients with small intramural uterine fibroids during IVF treatment. Hum Reprod;20:501506.

Ng EH, Chan CC, Tang OS, Yeung WS, Ho PC: (2006) The role of endometrial and subendometrial blood flows measured by three-dimensional power Doppler ultrasound in the prediction of pregnancy during IVF treatment. Hum Reprod, 21:164-170.

$\mathrm{Ng}$ EH, Chan CC, Tang OS, Yeung WS, Ho PC: (2006) The role of endometrial and subendometrial vascularity measured by three-dimensional power Doppler ultrasound in the prediction of pregnancy during frozen-thawed embryo transfer cycles. Hum Reprod, 21:1612-1617.

$\mathrm{Ng}$ EH, Yeung WS, Ho PC. (2009) Endometrial and sub endometrial vascularity are significantly lower in patients with endometrial volume $2.5 \mathrm{ml}$ or less. Reprod Biomed Online; 18:262-8.

Ng EHY, Chan CCW, Tang OS, Yeung WSB, Ho PC (2004). Endometrial and subendometrial blood flow measured during early luteal phase by three-dimensional power Doppler ultrasound in excessive ovarian responders. Human Reprod; 19: 924-31.

Ng EHY, Chan CCW, tang OS, Yeung WSB, Ho PC. (2004) Comparison of endometrial and subendometrial blood flow measured by three-dimensional power Doppler ultrasound between stimulated and natural cycles in the same patients. Hum Reprod; 19:2385-90.

Ng EHY, Chan CCW, tang OS, Yeung WSB, Ho PC. (2006) Factors affecting endometrial and subendometrial blood flow measured by three-dimensional power Doppler ultrasound during IVF treatment. Hum Reprod; 21: 1062-9

Nikas G, Develioglu OH, Toner JT. et al. (1999) Endometrial pinopodes indicate a shift in the window of receptivity in IVF cycles. Hum Reprod; 14:787-792.

Noyes N, Hapmton BS, Berkeley A, Licciardi F, Grifo J, Krey L. (2001) Factors useful in predicting the success of oocyte donation: a 3-year retrospective analysis. Fertil Steril; 76: 92-7.

Oliveira JB, Martins AM, Baruffi RL, Mauri AL, Petersen CG, Felipe V, Contart P, Pontes A and Franco Junior JG (2004) Increased implantation and pregnancy rates obtained by placing the tip of the transfer catheter in the central area of the endometrial cavity. Reprod Biomed Online 9,435-441. 
Pairleitner H, Steiner H, Hasenoehrl G, Staudach A: (1999) Three-dimensional power Doppler sonography: imaging and quantifying blood flow and vascularization. Ultrasound Obstet Gynecol, 14:139-143.

Poindexter AN, Thompson DJ, Gibbons WE, Findley WE, Dodson MG, Young RL (1986). Residual embryos in failed embryo transfer. Fertil Steril;46:262- 267.

Pope CS, Cook EKD, Arny M, Novak A and Grow DR (2004) Influence of embryo transfer depth on in vitro fertilization and embryo transfer outcomes. Fertil Steril81,51-58.

Prapas Y, Prapas N, Hatziparasidou A, Prapa S, Nijs M, Vanderzwal-men P, et al. (1995) The echoguide embryo transfer maximizes the IVF results. Acta Eur Fertil;26:113-5.

Prapas Y, Prapas N, Hatziparasidou A, Vanderzwalmen P, Nijs M, Prapa S and Vlassis G (2001) Ultrasound-guided embryo transfer maximizes the IVF results on day 3 and day 4 embryo transfer but has no impact on day 5. Hum Reprod16,19041908.

Rabinowitz, R., Laufer, N., Lewin, A., Navot, D., Bar, I., Margalioth, E.J. and Schenker, J.J (1986). The value of ultrasonographic endome-trial measurement in the prediction of preg-nancy following in vitro fertilization. Fertil. Steril;, 45, 824-8

Raga F, Bonilla-Musoles F, Casan EM, Klein O, Bonilla F: (1999) Assessment of endometrial volume by three-dimensional ultrasound prior to embryo transfer: clues to endometrial receptivity. Hum Reprod, 14:2851-2854.

Raine -Fenning NJ, Campbel BK, Clewes JS, Johnson IR (2004). Endometrial and subendomtrial perfusion are impaired in women with unexplained subfertility. Hum Reprod; 19: 2605-2614.

Raine-Fenning N, Campbell B, Collier J, Brincat M, Johnson I: (2002) The reproducibility of endometrial volume acquisition and measurement with the VOCAL-imaging program. Ultrasound Obstet Gynecol, 19:69-75.

Raine-Fenning NJ, Campbell BK, Clewes JS, Johnson IR: (2003) The interobserver reliability of ovarian volume measurement is improved with three-dimensional ultrasound, but dependent upon technique. Ultrasound Med Biol b, 29:1685-1690.

Raine-Fenning NJ, Campbell BK, Clewes JS, Kendall NR, Johnson IR: (2003) The reliability of virtual organ computer-aided analysis (VOCAL) for the semiquantification of ovarian, endometrial and subendometrial perfusion. Ultrasound Obstet Gynecol a, 22:633-639.

Raine-Fenning NJ, Campbell BK, Kendall NR, Clewes JS, Johnson IR: (2004) Quantifying the changes in endometrial vascularity throughout the normal menstrual cycle with three-dimensional power Doppler angiography. Hum Reprod, 19:330-338.

Rashidi BH, Sadeghi M, Jafarabadi M, Tehrani Nejad ES. (2005) Relationships between pregnancy ratios following in vitro fertilization or intracytoplasmic sperm injection and endometrial thickness and pattern. Eur J Obstet Gynecol Reprod Biol; 2: 179-84.

Reine-Fenning N, Campbell BK, Clewes JS, Kendall NG, Johnson IR. (2004) Defining endometrial growth during the menstrual cycle with three-dimensional ultrasound. Br j Obstet Gynaecol; 111: 944-9. 
Remohi J,Ardiles G, Garcia-Velasco JA, gaitan P, Simon C, Pellicer A. (1997) Endometrial thickness and serum oestradiol concentrations as predictors of outcome in oocyte donation. Hum Reprod; 12:2271-6

Riccabona M, Nelson TR, Pretorius DH. (1996) Three-dimensional ultrasound: accuracy of distance and volume measurements. Ultrasound Obstet Gynecol Jun; 7(6), 429-34.

Richter KS, Bugge KR, Bromer JG, Levy M. (2007) Relationship between endometrial thickness and embryo implantation, based on 1294 cycles of in vitro fertilization with transfer of two blastocyst-stage embryos. Fertil Steril; 1: 53-9.

Robert Z. Gergely, M.D.,Catherine Marin DeUgarte, M.D.,Hal Danzer, M.D.,Mark Surrey, M.D., David Hill, Ph.D. and Alan H. DeCherney, M.D. (2005) Three dimensional/four dimensional ultrasoundguided embryo transfer using the maximal implantation potential point. Fertility and Sterility 84: 500-503.

Roselund B, Sjöblom P and Hillensjö T (1996) Pregnancy outcome related to the site of embryo deposition in the uterus. J Assist Reprod Genet 13, 511-513.

Sallam HN and Sadek SS (2003) Ultrasound-guided embryo transfer: a meta-analysis of randomized controlled trials. Fertil Steril 80, 1042-1046.

Sallam HN, Agameya AF, Rahman AF, Ezzeldin F and Sallam AN (2002) Ultrasound measurement of the uterocervical angle before embryo transfer: a prospective controlled study. Hum Reprod 17,1767-1772.

Salle B, Bied-Damon V, Benchaib M, Desperes S, Gaucherand P, Rudigoz RC. (1998) Preliminary report of an ultrasonography and color Doppler uterine score to predict uterine receptivity in an in-vitro fer-tilization programme. Hum Reprod;13:1669-73.

Schild RL, Holthaus S, d'Alquen J, Fimmers R, Dorn C, van Der Ven H, Hansmann M: (2000) Quantitative assessment of subendometrial blood flow by three-dimensionalultrasound is an important predictive factor of implantation in an in-vitro fertilization programme. Hum Reprod, 15:89-94.

Schild RL, Indefrei D, Eschweiler S, Van der Ven H, Fimmers R, Hansmann M: (1999) Threedimensional endometrial volume calculation and pregnancy rate in an in-vitro fertilization programme. Hum Reprod, 14:1255-1258.

Schild RL, Knobloch C, Dorn C, Fimmers R, van der Ven H, Hansmann M: (2001) Endometrial receptivity in an in vitro fertilization program as assessed by spiral artery blood flow, endometrial thickness, endometrial volume, and uterine artery blood flow. Fertil Steril, 75:361-366.

Scholtes MCW, Wladimiroff JW, van Rijen HJM, Hop WCJ. (1989) Uterine and ovarian flow velocity waveforms in the normal menstrual cycle- a transvaginal study. Fertil Steril; 52:981-5.

Schoolcraft WB, Surrey ES and Gardner DK (2001) Embryo transfer: techniques and variables affecting success. Fertil Steril 76, 863-870.

Schulman JD (1986). Delayed expulsion of transfer fluid after IVF/ET. Lancet;1:44.

Scoutt LM, Flyn SD, Luthringer DJ, McCauley TR, McCarthy SM. (1991) Junctional zone of the uterus: correlation of MR imaging and histologic examination of hysterectomy specimens. Radiology;179:403-7. 
Serafini, P., Batzofin, J., Nelson, and Olive, D. (1994). Sonographic uterine predictors of pregnancy in women undergoing ovulation induction for assisted reproductive treatments. Fertil. Steril, 62,815-22

Shaker AG, Fleming R, Jamieson ME, Yates RW, Coutts JR (1993). Assessment of embryo transfer after in-vitro fertilization: effects of glyceryl trinitrate. Hum Reprod;8:14261428 .

Shamonki M, Schatman GL, Spandorfer SD and Rosenwaks Z (2005a) Ultrasound-guided embryo transfer may be beneficieal in preparation for an IVF cycle. Hum Reprod 20 (10),2844-49.

Shamonki MI, Spandorfer SD and Rosenwaks Z (2005b) Ultrasound-guided embryo transfer and the accuracy of trial embryo transfer. Hum Reprod 20(3),709-716.

Sharif K, Afnan M, Lenton W. Mock (1995) Embryo transfer with a full bladder immediately before the real transfer for in-vitro fertilization treatment: the Birmingham experience of 113 cases. Hum Reprod. Jul; 10(7): 1715-1718.

Sher G, Dodge S, Maassarani G, Knutzen V, Zouves C, Feinman M. (1993) Management of suboptimal sonographic endometrial patterns in pa-tients undergoing in-vitro fertilization and embryo transfer. Hum Re-prod;8:347-9.

Sher, G., Herbert, C, Maassarani, G. and Jacobs, M. H. (1991) Assessment of the late proliferative phase endometrium by ultra-sonography in patients undergoing in vitro fer-tilization and embryo transfer (IVF/ET). Hum. Reprod.; 6, 232-7

Sherer DM, Abulafia O: (2001) Angiogenesis during implantation, and placental and early embryonic development. Placenta, 22:1-13.

Sladkevicius P, Valentin L, Marsal K. (1993) Blood flow velocity in the uterine and ovarian arteries during the normal menstrual cycle. Ultrasound Obstet Gynecol; 3: 199208.

Smith, B., Porter, R., Ahuja, K. and Craft, I. (1984) Ultrasonic assessment of endometrial changes in stimulated cycles in an in vitro fertil-ization and embryo transfer program. J. In Vitro Fertil. Embryo Transfer, 1, 233-8

Steer, C V., Tan, S. L., Mason, B. A. and Campbell, S. (1994) Midluteal-phasc vaginal color Doppler assessment of uterine artery impedance in a subfertile population. Fertil. Steril; $61,53-8$

Steer, C. V., Campbell, S., Tan, S. L., Cravford, T, Mills, C, Mason, B. A. and Collins,' W. P. (1992). The use of transvaginal color flow imaging after in vitro fertilization to identify optimum uterine conditions before embryo transfer. Fertil. Steril; 57, $372-6$

Steptoe, P.C. and Edwards, R. (1976) Reimplantation of a human embryo with subsequent tubal pregnancy. Lancet, 1, $880-882$.

Sterzik, K., Grab, D., Sasse, V., Hutter, W., Rosenbusch, B. and Terinde, R. (1989) Doppler sonographic findings and their corre-lation with implantation in an in vitro fertiliza-tion program. Fertil. Steril; 52, 825-8

Strickler RC, Christianson C, Crane JP, Curato A, Knight AB and Yang V (1985) Ultrasound guidance for human embryo transfer. Fertil Steril 43, 54-61.

Sundstrom P, Wramsby H, Persson PH and Liedholm P (1984) Filled bladder simplifies human embryo transfer. Br J Obstet Gynaecol91,506-507. 
Sundtsrom P. (1998) Establishment of a successful pregnancy following in-vitro fertilization with an endometrial thickness of on more than $4 \mathrm{~mm}$. Hum Reprod; 13:1550-2

Tan SL, Biljan MM. (2000) Selection of candidates for in vitro fertilization based on color Doppler findings. In Kupesic S, De Ziegler D, (Eds): Ultrasound and Infertility. London: the Prathenon Publishing Group; 155-68

Tan SL, zaidi J, Campbell S, Doyle P, Collins W. (1996) Blood flow changes in the ovarian and uterine arteries during the normal menstrual cycle. Am j obstet Gynecol; 175:625-31

Tang B, Gurpide E. (1993) Direct effect of gonadotropins on decidualization of human endometrial stroma cells. J Steroid Biochem Mol Biol; 47:115-21

Tang OS, Ng EHY, So WWK and Ho PC (2001) Ultrasound-guided embryo transfer: a prospective randomized controlled trial. Hum Reprod16,2310-2315.

Tekay A, Martikainen H, Jouppila P. (1996) The clinical value of transvaginal color Doppler ultrasound in assisted reproductive technology proce-dures. Hum Reprod;11:1589_ 91.

Tekay A, Martikainen H, Jouppila P: (1995) Blood flow changes in uterine and ovarian vasculature, and predictive value of transvaginal pulsed color Doppler ultrasonography in an in-vitro fertilization programme. Hum Reprod, 10:688693.

Tetlow RL, Richmond I, Manton DJ, Greenman J, Turnbull LW, Killick SR. (1999) Histological analysis of the uterine junctional zone as seen by transvaginal ultrasound. Ultrasound Obstet Gynecol;14:188- 93.

Tsai HD, Chang CC, Hsieh YY, Lee CC, Lo HY. (2000) Artificial insemination. Role of endometrial thickness and pattern, of vascular impedance of the spiral and uterine arteries, and of the dominant follicle. J Reprod Med; 3: 195-200.

Turnbull LW, Manton JD, Horsman A, Killick SR. (1995) Magnetic resonance imaging changes in uterine zonal anatomy during a conception cycle. $\mathrm{Br} \mathrm{J}$ Obstet Gynaecol;102:330-1.

Van de Pas MMC, Weima S, Looman CWN and Broekmans FJM (2003) The use of fixed distance embryo transfer after IVF/ICSI equalizes the success rates among physicians. Hum Reprod 18, 774-780.

Visser, D.S., Fouri, F.L. and Kruger, H.F. (1993) Multiple attempts at embryo transfer: effect on pregnancy outcome in an in vitro fertilization and embryo transfer program. J. Assist. Reprod. Genet., 10, 37-43.

Waterstone, J., Curson, R. and Parsons, J. (1991) Embryo transfer to low uterine cavity. Lancet, 337, 1413.

Weissman A, Gotlieb L, Casper RF. (1999) The detrimental effect of increased endometrial thickness on implantation and pregnancy ratios and outcome in an in vitro fertilization program. Fertil Steril; 1: 147-9.

Welker, B. G., Gembruch, U., Diedrich, K., al-Hasani, S. and Krebs, D. (1989) Transvagi-nal sonography of the endometrium during ovum pick-up in stimulated cycles for in vitro fertilization./. Ultrasound Med , 8, 549-53 
Wisanto A, Janssens R, Deschacht J, Camus M, Devroey P, Van Steirteghem AC. (1989) Performance of different embryo transfer catheters in a human in vitro fertilization program. Fertil Steril. Jul; 52(1): 79-84.

Wood C, McMaster R, Rennie G, Trounson A and Leeton J (1985) Factors influencing pregnancy rates following in vitro fertilization and embryo transfer. Fertil Steril 43,245-250.

Wood EG, Batzer FR, Go KJ, Gutmann JN, Corson SL. (2000) Ultrasound-guided soft catheter embryo transfers will improve pregnancy rates in in-vitro fertilization. Hum Reprod. Jan; 15(1): 107-112.

Woolcott R and Stanger J (1997) Potentially important variables identified by transvaginal ultrasound-guided embryo transfer. Hum Reprod 12, 963-966.

Woolcott R, Stanger J (1998). Ultrasound tracking of the movement of embryo-associated air bubbles on standing after transfer. Hum Reprod;13:2107-9.

Wu HM, Chiang CH, Huang HY, Chao AS, Wang HS, Soong YK: (2003) Detection of the subendometrial vascularization flow index by three-dimensional ultrasound may be useful for predicting the pregnancy rate for patients undergoing in vitro fertilization- embryo transfer. Fertil Steril, 79:507-511.

Yaman C, Ebner T, Sommergruber M, Polz W, Tews G. (2000) Role of three-dimensional ultrasonographic measurement of endometrium volume as a predictor of pregnancy outcome in an IVF-ET program: a preliminary study. Fertil Steril; 74(4): 797-801.

Yaman C, Jesacher k, Polz W: (2003) Accuracy of three-dimensional transvaginal ultrasound in uterus volume measurements: comparison with two-dimensional ultrasound. Ultrasound Med boil; 29;1681-1684

Yaman C, Sommergruber M, Ebner T, Polz W, Moser M, Tews G: (1999) Reproducibility of transvaginal three-dimensional endometrial volume measurements during ovarian stimulation. Hum Reprod, 14:2604-2608.

Yang J-H, Wu M-Y, Chen C-D, Jiang M-C, Ho H-N, yang Y-S. (1999) Association of endometrial blood flow as determined by a modified color Doppler technique with subsequent outcome of in-vitro fertilization. Hum reprod; 14;1606-10.

Yuval Y, Liptz S, Dor J, Achiron R. (1999) The relationship between endometrial thickness, and blood flow and pregnancy rates in in-vitro fertilization. Human Reprod; 14:1967-71

Zaidi J, Campbell S, Pittrof R, tan SL. (1995) Endometrial thickness, morphology, vascular penetration and velocimetry in predicting implantation in an in vitro fertilization program. Ultrasound Obstet Gynecol; 6; 191-8

Zaidi, J., Pittrof, R., Shaker, A, Kyei-Mensah, A., Campbell, S. and Tan, S. L. (1996) Assessment of uterine artery blood flow on the day of human chorionic gonadotropin administration by transvaginal color Doppler ultrasound in an in vitro fertilization program. Fertil. Steril; 65,377-81

Zech, H., Stecher, A., Riedler, I. et al. (1997) High implantation rate with a fast and atraumatic embryo transfer technique. Hum. Reprod., 12 (Abstract Bk 1), p. 156 
Zhang X, Chen CH, Confino E, Barnes R, Milad M, Kazer RR. (2005) Increased endometrial thickness is associated with improved treatment outcome for selected patients undergoing in vitro fertilization-embryo transfer. Fertil Steril; 2: 336-40.

Zollner U, Zollner KP, Specketer MT, Blissing S, Muller T, Steck T, Dietl J: (2003) Endometrial volume as assessed by three dimensional ultrasound is a predictor of pregnancy outcome after in vitro fertilization and embryo transfer. Fertil Steril; 80:1515-1517.

Zouves C, Erenus M, Gomel V (1991). Tubal ectopic pregnancy after in vitro fertilization and embryo transfer: a role for proximal occlusion or salpingectomy after failed distal tubal surgery. Fertil Steril;56: 691-695. 


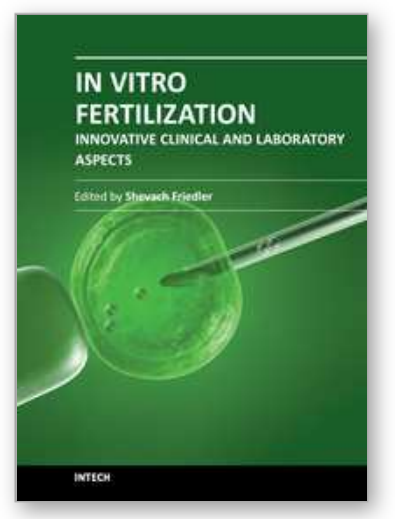

\author{
In Vitro Fertilization - Innovative Clinical and Laboratory Aspects \\ Edited by Prof. Shevach Friedler
}

ISBN 978-953-51-0503-9

Hard cover, 156 pages

Publisher InTech

Published online 11, April, 2012

Published in print edition April, 2012

The field of In Vitro Fertilization is a relatively new field in medicine, constantly on the move. This field is an exquisite example of the vast power in the complementary use of basic research with clinical practice and opened a new route of great basic and clinical research possibilities. The knowledge base that allowed the accomplishment of the idea of in vitro fertilization and embryo transfer has much developed since. The vast body of research pertaining to this field allowed deepening our understanding in the processes related to reproduction. In this book on in vitro fertilization we present new and interesting updated information in various aspects of this field. This work is a result of collaborative work of an international group of professionals dedicated to contribute to the advancement of our knowledge.

\title{
How to reference
}

In order to correctly reference this scholarly work, feel free to copy and paste the following:

Mitko Ivanovski (2012). The Role of Ultrasound in the Evaluation of Endometrial Receptivity Following Assisted Reproductive Treatments, In Vitro Fertilization - Innovative Clinical and Laboratory Aspects, Prof. Shevach Friedler (Ed.), ISBN: 978-953-51-0503-9, InTech, Available from: http://www.intechopen.com/books/in-vitrofertilization-innovative-clinical-and-laboratory-aspects/the-role-of-ultrasound-in-the-evaluation-of-endometrialreceptivity-following-assisted-reproductive-

\section{INTECH}

open science | open minds

\author{
InTech Europe \\ University Campus STeP Ri \\ Slavka Krautzeka 83/A \\ 51000 Rijeka, Croatia \\ Phone: +385 (51) 770447 \\ Fax: +385 (51) 686166 \\ www.intechopen.com
}

\author{
InTech China \\ Unit 405, Office Block, Hotel Equatorial Shanghai \\ No.65, Yan An Road (West), Shanghai, 200040, China \\ 中国上海市延安西路65号上海国际贵都大饭店办公楼 405 单元 \\ Phone: +86-21-62489820 \\ Fax: $+86-21-62489821$
}


(C) 2012 The Author(s). Licensee IntechOpen. This is an open access article distributed under the terms of the Creative Commons Attribution 3.0 License, which permits unrestricted use, distribution, and reproduction in any medium, provided the original work is properly cited. 